\title{
Audit Quality and Investment Efficiency with Informed Trading
}

August 29, 2018

\begin{abstract}
We study how informed, strategic trading affects audit quality and investment efficiency. With the auditor's damage payment due to legal liability based on the decrease in the market price after an audit failure, we show that informed trading provides a hedge to the auditor against legal liability risk, and weakens incentives for audit quality. In turn, the strategic trader produces more information due to higher gains from trade that are made available by lower audit quality. Moreover, the behavior of liquidity traders affects both audit quality and the extent of informed trading, and is not monotonically related. A stricter legal liability regime leads to higher audit quality and less informed trading. However, prices can be used to guide real investments, such as corporate expansions and stricter liability might lead to lower investment efficiency because with less informed trading, market prices are less informative.
\end{abstract}

JEL classification: M41, M42, G14, G23, G32

Keywords: Auditor liability; financial reporting quality; informed trading; information production; real capital investment 


\section{Introduction}

Prices in financial markets are shaped by the ongoing flow of public information, e.g., audited financial statements, and by the trading behavior of market participants, such as informed traders. ${ }^{1}$ In this respect, auditors play a key role as they provide credibility to a firm's financial statements; higher audit quality improves financial reporting quality and contributes to leveling the playing field for market participants and bringing prices closer to fundamentals. ${ }^{2}$ At the same time, price imperfections provide strategic investors an incentive to acquire private information and profit from trade. ${ }^{3}$ Thus, the accuracy of financial statements, as influenced by audit quality, and the information contained in the trading behavior of strategic, informed investors affects price efficiency. We explore how an auditor's choice of audit quality and a strategic trader's information production shape price efficiency in the market and the efficiency of a firm's investment.

Potential legal liability damages from shareholder lawsuits provide a strong motivation for auditors to provide high audit quality. In the event of audit failure, the larger the share-price correction and consequent shareholder losses, the greater is the potential for auditor liability (e.g., Lys and Watts, 1994). ${ }^{4}$ While some audit failures result in abrupt downward price movements, in other cases information finds its way into prices, e.g., through other sources of information or informed trading. Thus, the presence of informed traders in the market indirectly affects the auditor's legal liability: the less that market prices reflect fundamentals prior to the correction, the more that market prices will respond to the audit failure and the higher will be the auditor's legal liability damage payment. We explore the implications that market liquidity and auditor legal liability have for audit quality and the extent of informed trading.

One avenue that regulators use to improve the efficiency of investment decisions that provide firms with potential growth opportunities, such as corporate expansions, is through stricter au-

\footnotetext{
${ }^{1}$ It is not unusual for prices to move as a response to releases of accounting information or changes in order flow. See Beaver (1968) and Ball and Brown (1968) for early analyses of the reaction of price to earnings announcements and Chordia and Subrahmanyam (2004) and Griffin, et al. (2003) for analyses of the reaction of prices to the information contained in order flow.

${ }^{2}$ This is consistent with PCAOB's stated view that its responsibilities "are all ultimately directed at improving audit quality and thereby benefiting investors" (PCAOB, 2015).

${ }^{3}$ For example, see Glosten and Milgrom (1985), Kyle, (1985), and Easley and O'Hara (1987).

${ }^{4}$ Typically, damage payments imposed on auditors are based on the difference between the higher price at the time of purchase, and the lower, subsequent price once the firm's value is determined. See, for example, page 109 Stat. 749 of the Private Securities Litigation Reform Act of 1995, which states that "the award of damages to the plaintiff shall not exceed the difference between the purchase or sale price paid or received, as appropriate, by the plaintiff for the subject security and the mean trading price of that security during the 90-day period beginning on the date on which the information correcting the misstatement or omission that is the basis for the action is disseminated to the market."
} 
ditor legal liability. For example, the intent of the Sarbanes-Oxley Act of 2002 was to improve market efficiency by providing more transparency to market participants; although it did not directly increase auditor liability, arguably, it strengthened the auditor's legal liability environment. With market prices depending on both the audited financial statements and the strategic trader's information, we consider how informed, strategic trading and the strictness of the auditor's legal liability regime affect investment efficiency.

In our setting, a firm hires an auditor to verify its earnings, which are publicly released to a financial market, in which participants trade in the firm's shares. The firm's fundamental state of productivity can be high or low and this information is reflected (imperfectly) in its earnings report. The auditor provides a level of assurance about the firm's earnings report by privately choosing audit quality. Audit failure occurs when the audit report overstates the firm's value, which is observed subsequent to the audit report. In this case, shareholders may sue the auditor, who may be found liable for their damages.

The auditor's legal liability depends on whether the price decreases after audit failure is observed. We assume that the auditor's legal liability consists of two parts: (i) the probability of being sued and found liable, which, similar to Choi, et al. (2008) and Laux and Newman (2010), we interpret as the strictness of the legal liability regime; (ii) the damage payment, which is the decrease in the price upon learning the firm's terminal value, i.e., the short-term price given the audit report less the price upon observation of the firm's terminal value. The auditor's expected liability is higher with a stricter legal liability regime, because it is more likely that the auditor is sued and found liable for shareholder losses. and the larger the price decrease, the greater the auditor's damage payment.

Consistent with the microstructure literature, i.e., as in Kyle (1985) and Glosten and Milgrom (1985), we assume that the market consists of two types of traders (Grossman and Stiglitz, 1980): a liquidity trader and a strategic investor that trade by submitting market orders to a risk neutral, competitive market maker. The strategic trader devotes resources to produce information and with some probability, is informed about the firm's value, which he uses to take advantage of market mispricing. The market maker sets prices based on the firm's expected terminal value, given the audit report and the aggregate order flow, i.e., the total market orders of the strategic and liquidity traders. Due to the presence of informed traders, short-term prices might reflect fundamental values and, in this case, the auditor does not face liability because there is no price correction at the time that the audit failure becomes public. Thus, aside from the audited financial statements, informed 
trading is a mechanism by which prices remain close to fundamentals and, by doing so, reduces the auditor's expected liability.

We show that audit quality and informed trading are strategic substitutes. That is, informed trading provides a hedge to the auditor against liability risk that emerges from mispricing, and mitigates the incentives for audit quality. Thus, the more the strategic investor allocates to information production, the lower is the extent of mispricing and the lower is the auditor's choice of audit quality. On the other hand, the higher the audit quality, the less the strategic trader devotes resources for information production, implying that short-term prices are more efficient and reflect the firm's value, which leaves less potential for gains from trade.

The distribution of the liquidity trader's demand affects both audit quality and the extent of informed trading in a non-monotonic fashion. Intuitively, the strategic trader's information production efforts depend on his ability to hide behind, so to speak, the liquidity trader. With less uncertainty regarding the demand of liquidity trader, i.e., a less liquid market ala Kyle (1985), it is more difficult for the informed trader to hide his trades and profit from trade, and thus, the strategic trader responds by decreasing information production. With more uncertainty about the demand of liquidity trader, then prices reflect fundamentals to a lesser extent. All else equal, the auditor is motivated to choose higher audit quality due to higher liability. In equilibrium, the auditor also responds to the strategic trader's information production. Together, this implies that there is non-monotonic association between the liquidity trader's demand and audit quality.

The strictness of the legal liability regime increases audit quality and leads to less informed trading in equilibrium. Intuitively, the auditor responds to stricter liability by increasing audit quality to reduce the likelihood of audit failure. The informed trader responds to higher audit quality with less informed trading. In addition, with stricter liability, the decrease in prices upon the realization of audit failure is smaller, which means that the informed trader earns less profit from trading, and responds with lower information production. Overall, for both reasons, the strategic trader responds to stricter liability by reducing information production.

When real investment by the firm is guided by market prices (as in Bond, et al., 2010), audit failure can cause efficiency losses due to overinvestment in a low value firm, i.e., when the investment has a negative net present value. However, investors base their beliefs about the value of the growth option on both the audit report and on market prices. With stricter legal liability, as imposed by a regulator, audit quality is higher but informed trading is lower, and it is possible that overall investment efficiency and firm value are lower. In particular, this is the case when the value of 
the growth option is relatively low, i.e., when the added information provided by informed trading is essential for investment to occur. On the other hand, when the value of the growth option is higher and investment may take place even when prices are less informative about firm value, the reduction in informed trading as a result of stricter liability can have a second-order effect on investment efficiency, i.e., overall, in equilibrium, an increase in audit quality may increase investment efficiency.

This paper is related to prior work on the impact of legal liability on audit quality and investment. Dye (1993) shows that with legal liability due to negligence, auditor wealth is a key factor in the level of audit quality, where higher audit quality increases firm value as it reduces the likelihood of overinvestment. More recently, Rothenberg (2018) considers whether legal liability due to negligence can weaken or strengthen the auditor's reputation concerns, and studies the joint effect on investors' and the auditor's preferences for noncompliance and lower audit quality. Schwartz (1997) shows that with strict liability and when the damage payment depends on the investors' loss, the insurance role of auditor liability encourages investors to overinvest in risky projects. Newman, et al. (2005) show that higher audit penalties result in higher audit quality, less diversion of resources, and more investment. In contrast, Deng, et al. (2012) shows that an increase in the auditor's liability causes investment in new projects to decrease because of the increase in false negative (Type I) auditing errors, which means that a firm's financial statements are more likely to be understated. Our paper highlights the role of strategically informed trading in shaping the auditor's legal liability damage payment and in how the strictness of the auditor's legal liability can lower investment efficiency.

Prior literature has considered the trading behavior of strategically informed investors when market participants can learn about firm value from the firm's public announcements. McNichols and Trueman (1994) analyze the trading behavior of short-term investors before a scheduled public disclosure and find that higher quality public disclosures provide incentives for higher quality private information acquisition before the disclosure. Demski and Feltham (1994) show that an exogenous increase in the quality (or informativeness) of the firm's disclosure can either increase or decrease the variance of the market return, when traders can acquire early information about the firm's disclosure.

Other work considers the trading behavior surrounding voluntary firm disclosures. Kumar, et al. (2016) consider how informed trading at the time of an IPO affects the disclosure behavior of the manager and the level of underpricing, and Kumar, et al. (2017) consider the information 
production by informed traders following firm disclosures when managers can repurchase shares. Einhorn (2018) considers the voluntary disclosure decision of managers when not all of their private information can be credibly disclosed and informed traders can trade on this information. Relatedly, Frenkel, et al. (2017) consider the disclosure behavior of a manager when informed traders can trade following the release of a public analyst forecast, and Petrov (2016) considers informed trading following a public disclosure by a manager when managerial private information is valuable and disclosures are costly. Finally, Goldstein and Yang (2017) analyze information disclosure in financial markets when market prices can also guide real investments and real investment. We also consider the role of information production by informed traders surrounding a public signal - which, in our case, is the audit report. However, we model the auditor's choice of the accuracy of the public signal by explicitly considering that the auditor's liability is given by the decrease in market prices following audit failure. With information production by strategic traders, we jointly determine the information embedded in the audit signal and market prices, and the implications of auditor liability for the efficiency of prices and investment.

\section{Model}

Consider a firm with terminal value $v, v \in\left\{v_{\ell}, v_{h}\right\}$, where the firm's value is $v_{\ell}$ in the low productivity state, and $v_{h}$ in the high productivity state with $0 \leq v_{\ell}<v_{h}$. The probability that the firm's value is high, i.e., $v_{h}$, is $\lambda$. The firm has no private information about its productivity and is required to hire an auditor to generate a public signal regarding firm value, $s \in\left\{s_{\ell}, s_{h}\right\}$, in exchange for a noncontingent fee of $\varphi \geq 0$. We denote the firm's net value, by $V=v-\varphi$. The precision of the auditor's public signal depends on her private choice of audit quality, $a \in[0,1)$ with cost $-\operatorname{cln}(1-a)$ for some positive parameter $c>0 .^{5}$ The auditor can perfectly identify a firm with high terminal value, i.e., $\operatorname{Pr}\left(s_{h} \mid v_{h}\right)=1$. However, if the firm's productivity state is low, then whether the audit signal is low depends on the audit quality, or $\operatorname{Pr}\left(s_{\ell} \mid v_{\ell}\right)=a$. The joint distribution of firm value and the auditor's signal is given by,

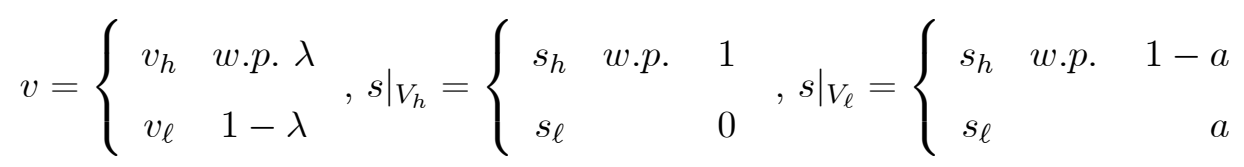

\footnotetext{
${ }^{5}$ The cost function $c(a)=-c \ln (1-a)$ has the desirable properties: $c(a) \geq 0, c^{\prime}(a)>0$, and $c^{\prime \prime}(a)>0$ for all $a \in[0,1)$. We consider this form of cost function for exerting effort by the auditor because it yields a closed form solution. Our results continue to hold with a quadratic cost function, i.e., $c(a)=c a^{2}$.
} 
We consider a simple model with four dates: $t \in\{0,1,2,3\}$. The shares of an all equity firm, with the total number of outstanding shares normalized to 1 , are traded at times $t=0,2$, and 3 . Market participants are rational and prices satisfy $P_{t}=E\left(P_{T}\right)$ for any $t<T$, where $t, T \in\{0,2,3\}$. We ignore the time value of money.

At the initial date $t=0$, information regarding the value of the firm is symmetric, and the market price is denoted by $P_{0}$. At that time, the auditor privately chooses audit quality, $a$. At $t=1$, the audit signal, $s$ is publicly observed; we assume that the auditor cannot manipulate the outcome of the audit before the signal is publicly observed. ${ }^{6}$ At time $t=2$, following the audit signal, shares are publicly traded, i.e., current shareholders and other market participants can buy or sell shares in the market. At this time, the short-term stock price, $P_{2}$, is determined. Finally, at time $t=3$, the true value of the firm is realized, $v$. The terminal stock price at time $t=3$ is given by the sum of net firm value, $V$, and any liability by the auditor, $\beta L$, where $\beta$ is the likelihood that shareholders sue the auditor and the auditor is found liable for the shareholders' loss, and $L$ is the liability damage payment. We discuss the liability payment in more detail below.

We follow the microstructure literature, i.e., as in Kyle (1985) and Glosten and Milgrom (1985), by assuming that the market for the firm's shares consists of two types of investors (Grossman and Stiglitz, 1980): a liquidity trader and a strategic investor that trade by submitting market orders to a risk neutral competitive market maker. For simplicity, we utilize a binary representation of the Kyle (1985) market mechanism (e.g., Bernhardt et al.,1995; Maug, 1998). At the beginning of $t=2$, the noise trader realizes an uninsurable liquidity shock and must buy or sell $q \in\{\Delta,-\Delta\}$ shares. In particular, the liquidity shock, $q$, is to buy (sell) $\Delta$ with probability $\theta(1-\theta)$, independent of the value $v$.

$$
q=\left\{\begin{array}{rrr}
\Delta & w . p & \theta \\
\Delta & 1-\theta
\end{array}\right.
$$

It is likely, however, that highly sophisticated market participants know the value of the firm. The strategic trader privately observes a precise signal, i.e., $\omega=v$, with probability $\rho \in(0,1)$, and, otherwise, receives no signal, i.e., $\omega=\phi$. We denote the event that the strategic trader is informed by $\Phi=1$, and otherwise $\Phi=0$. Formally,

$$
\operatorname{Pr}(\omega=v)=\rho, \text { and } \operatorname{Pr}(\omega=\phi)=1-\rho, \text { for } \rho \in(0,1) \text { and } v \in\left\{v_{\ell}, v_{h}\right\} .
$$

\footnotetext{
${ }^{6}$ We abstract from issues concerning reporting discretion or bias by the auditor and rather focus on the choice of audit quality. For an analysis that considers such discretion, e.g., auditor conservatism, see Lu and Sapra (2009).
} 
The extent to which the strategic trader is able to observe the firm's value depends on his due diligence or effort exerted in information production and analysis. We introduce information production subsequently after establishing the equilibrium for a given (or exogenous) likelihood that the strategic trader is informed.

Due to the binary nature of the distribution of the noise trader's liquidity shock, we follow the literature and consider the behavior of the strategic trader that consists of either buying or selling $r \in\{\Delta,-\Delta\}$ shares. This allows the strategic trader to hide behind liquidity traders, so to speak, and benefit from trade. The aggregate order flow is given by,

$$
F \equiv r+q
$$

A market maker observes the order flow and the audit signal and then sets prices. The market maker is risk neutral and only observes the aggregate order flow, $F$, because $r$ and $q$ are not directly observable. Thus, the price at time $t=2$ is the expected value of terminal price $P_{3}$ conditional on the the audit signal and aggregate order flow, denoted $P_{2}(s . F)$. We assume free entry in marketmaking (Kyle, 1985), which means that prices are set so that the market maker breaks even on average. Figure 1 shows the game tree and the relation among the firm's fundamental value, the audit signal, and the prices at time $t=2$.

\section{Insert Figure 1 here}

If, following the audit signal, the market price is higher than the firm's fundamental value, $v$, then shareholders may sue auditor, who may be found liable for the shareholders' loss. Similar to Laux and Newman (2010), we assume that the auditor is sued and found liable with probability $\beta \in(0,1)$. We refer to the variable $\beta$ as the strictness of the legal liability regime.

If the auditor is sued and found liable, then the legal liability damage payment is equal to the decrease in the price, i.e., similar to an out of pocket damage payment. The auditor may incur a liability only when two conditions are satisfied: (i) the auditor over-reported the firm's value as high, $s_{h}$, when the firm's value was actually low, $v_{\ell}$; (ii) there is a decline in the price upon the realization of the true firm type. The shareholders' loss in this case is captured by the decrease in price upon the public observation of the firm's output, $P_{2}\left(s_{h}, F\right)-P_{3}\left(V_{\ell}, s_{h}\right)$. The liability payment is therefore given by, 


$$
L=\left\{\begin{array}{cc}
\max \left(P_{2}-P_{3}, 0\right) & \left\langle V_{\ell}, s_{h}\right\rangle \\
0 & \text { otherwise }
\end{array} .\right.
$$

The above implies that there is no liability following a low audit signal, $s_{\ell}$, because the low signal is perfectly accurate. There is also no liability when the audit signal is high, $s_{h}$, and firm's value is high, $v_{h}$, because the price at time $t=3$ increases upon the public realization of the true firm value.

The auditor's expected payoff consists of the noncontingent audit fee paid ex-ante by the firm, the expected liability damages, and the costs associated with audit quality,

$$
U^{A}=\varphi-(1-\lambda)(1-a) \beta E\left(L \mid V_{\ell}, s_{h}\right)+\operatorname{cln}(1-a) \text { where } L \text { is given by }(2) \text {. }
$$

The sequence of events is as follows:

1. Nature chooses the firm's unobservable fundamental value, $v$. The firm hires an auditor and pays a fee, $\varphi$, which is set competitively. Then, the auditor privately chooses audit quality, $a$.

2. The auditor's public signal, $s$, is realized.

3. Trade takes place at price $P_{2}$.

4. Terminal cash flow, $V$, is realized and $P_{3}=V+\beta L$.

5. If the auditor over-reported the firm's value, shareholders may sue auditor, who, if found to be liable, makes a liability payment, $L$ to shareholders.

We analyze the Perfect Bayesian equilibrium (PBE) of the game set up by the time line above. The PBE consists of:

The Auditor's choice of audit quality: the auditor privately chooses audit quality, a, while anticipating the trading behavior of the strategic trader, the prices set by the market maker, and her expected liability given audit failure.

The Strategic Trader's strategy: the strategic trader's strategy, $r(\omega)$, is optimal given her information $\omega$ and her Bayes-consistent beliefs about the market maker's pricing function $P_{2}(F, s)$ and the auditor's strategy.

The Market Maker's price setting: the short-term price, $P_{2}$, and terminal price, $P_{3}$, can depend on the order flow and the auditor's signal, and are set such that the market maker breaks even on 
average, given her Bayes-consistent beliefs about audit quality and the informed investor's trading strategy.

A PBE, then, is the profile $\mathcal{S}^{*}=\left\langle a, r,\left\langle P_{2}(F, s), P_{3}\right\rangle\right\rangle$ where the auditor's strategy and the strategic trader's strategy are optimal given the competitive prices $\left\langle P_{2}(F, s), P_{3}\right\rangle$, and the market maker's pricing is optimal given the auditor's and strategic trader's strategy.

Before delving into the equilibrium analysis, it is useful to note that in any equilibrium, given the expected liability, $E\left(L \mid V_{\ell}, s_{h}\right)$, the auditor privately chooses audit quality, $a \geq 0$, by maximizing his expected payoff in $U^{A}$, as follows,

$$
a^{*}\left(E\left(L \mid V_{\ell}, s_{h}\right)\right)=\max \left(1-\frac{c}{(1-\lambda) \beta E\left(L \mid V_{\ell}, s_{h}\right)}, 0\right)
$$

and the corresponding noncontingent fee to the auditor, $\varphi$, is set competitively to yield zero rents,

$$
\varphi^{*}\left(E\left(L \mid V_{\ell}, s_{h}\right)\right)=(1-\lambda)\left(1-a^{*}\right) \beta E\left(L \mid V_{\ell}, s_{h}\right)-\operatorname{cln}\left(1-a^{*}\right) .
$$

Of course, we will derive the equilibrium value of the expected liability as endogenously determined by informed trading.

\section{Benchmark, No Informed Trading}

In this section, we consider a benchmark case in which the strategic trader has no information, i.e., $\rho=0$. With no informed trading, denote the liability damage payment conditional on an over-statement by the auditor as $L_{0}$.

With no informed trading, the market maker will set short-term prices independent of order flow, $F$, but will take into account the audit signal, $s$, when determining prices. Following a low audit signal, $s_{\ell}$, there is no residual uncertainty, because $\operatorname{Pr}\left(v_{\ell} \mid s_{\ell}\right)=1$. Therefore, the price will perfectly reflect fundamentals, there are no opportunities for the strategic trader to gain from trade, and the auditor is not subject to any future liability. In particular, the price given a low audit signal, $s_{\ell}$, is:

$$
P_{2}\left(s_{\ell}\right)=P_{3}\left(V_{\ell}, s_{\ell}\right)=V_{\ell}
$$

The case of interest is when the audit signal is high, $s_{h}$. The market price must reflect the possibility of a mistake by the auditor and incorporate the aforementioned liability payment. Working backwards from time $t=3$, when the true value of the firm is publicly observable, we can derive 
the terminal price, which is simply the sum of the net firm value and any liability payment made by the auditor, i.e., $P_{3}=V+\beta L_{0}$. At time $t=2$, rational expectations imply a consistent market price such that $P_{2}\left(s_{h}\right)=E P_{3}\left(V, s_{h}\right)$. Formally, the time $t=2$ price following a high audit signal is given by,

$$
\begin{aligned}
P_{2}\left(s_{h}\right) & =\lambda_{0} P_{3}\left(V_{h}, s_{h}\right)+\left(1-\lambda_{0}\right) P_{3}\left(V_{\ell}, s_{h}\right), \text { where } \\
\lambda_{0} & \equiv \operatorname{Pr}\left(V_{h} \mid s_{h}\right)=\frac{\lambda}{\lambda+(1-\lambda)(1-\hat{a})}
\end{aligned}
$$

Following the high audit signal, the conditional likelihood that the true firm value is high, or $\lambda_{0}$, depends on the audit quality chosen by the auditor, $a$. The auditor's choice of audit quality is, of course, unobservable to market participants and, therefore, beliefs are based on its conjectured level, $\hat{a}$. As expected, the higher the conjectured level of audit quality, the more likely it is that the firm's true output is high conditional on a high audit signal.

Turning to time $t=3$ prices, consider first the event $v_{h}$ and audit signal $s_{h}$. In this case, there will be no liability damage payment, and therefore, the terminal price reflects the high value, i.e., $P_{3}\left(V_{h}, s_{h}\right)=V_{h}$. However, in the event $v_{\ell}$ and audit signal $s_{h}$, the expected damage payment, $\beta L_{0}$, is reflected in the price, i.e., $P_{3}\left(V_{\ell}, s_{h}\right)=V_{\ell}+\beta L_{0}$. In turn, the damage payment depends on the intertemporal drop in prices $L_{0}=P_{2}\left(s_{h}\right)-P_{3}\left(V_{\ell}, s_{h}\right)$, and is given by,

$$
\begin{aligned}
L_{0} & =\left[\lambda_{0} P_{3}\left(V_{h}, s_{h}\right)+\left(1-\lambda_{0}\right) P_{3}\left(V_{\ell}, s_{h}\right)\right]-P_{3}\left(V_{\ell}, s_{h}\right) \\
& =\lambda_{0}\left[V_{h}-P_{3}\left(V_{\ell}, s_{h}\right)\right] .
\end{aligned}
$$

Then the expected damage payment, $\beta L_{0}$, is reflected in the price $P_{3}\left(V_{\ell}, s_{h}\right)$ as follows:

$$
P_{3}\left(V_{\ell}, s_{h}\right)=V_{\ell}+\beta L_{0}=V_{\ell}+\beta \lambda_{0}\left[V_{h}-P_{3}\left(V_{\ell}, s_{h}\right)\right]
$$

This implies that,

$$
P_{3}\left(V_{\ell}, s_{h}\right)=V_{\ell}+\frac{\beta \lambda_{0}\left(V_{h}-V_{\ell}\right)}{1+\beta \lambda_{0}}, \text { and } P_{3}\left(V_{h}, s_{h}\right)=V_{h}
$$

The damage payment can be expressed in terms of fundamentals as follows,

$$
L_{0}=\frac{\lambda_{0}\left(V_{h}-V_{\ell}\right)}{1+\beta \lambda_{0}}=\frac{\lambda\left(V_{h}-V_{\ell}\right)}{\lambda(1+\beta)+(1-\lambda)(1-\hat{a})} .
$$


Note that the higher the conjectured level of audit quality, $\hat{a}$, the higher is the updated belief that the firm value is high, or $\lambda_{0}$, and consequently, the higher is the damage payment $L_{0}$. This follows because the damage payment is proportional to the price drop upon the observation of $v_{\ell}$. When shareholders have more confidence in the audit signal, the surprise upon realization of $v_{\ell}$ leads to a sharper price decline and a greater loss to shareholders. In addition, for a given level of audit quality, $\hat{a}$, the damage payment, $L_{0}$, is decreasing in the strictness of the legal liability regime, $\beta$. This is because a stricter legal liability regime means that the terminal price when the firm's fundamental value is low, but the audit signal is high, $P_{3}\left(V_{\ell}, s_{h}\right)$, is higher because the likelihood of a damage payment is higher. With a higher terminal price, the price decrease in the event of audit failure is lower.

We now return to the second period price, and incorporate the above derivations to obtain,

$$
P_{2}\left(s_{h}\right)=V_{\ell}+\frac{(1+\beta) \lambda_{0}}{1+\beta \lambda_{0}}\left(V_{h}-V_{\ell}\right)
$$

To appreciate the implications of the strictness of the legal liability regime, $\beta$, on market prices for a conjectured level of audit quality, $\widehat{a}$, we consider the two extreme cases of $\beta=0$, i.e., no liability, and $\beta=1$, i.e., strict liability. In the former case, the expected damage payment is zero, which means that audit quality is zero, or $a=0$, and the terminal prices are $P_{3}=V$. With no liability and no auditing, the price at time $t=2$ is the same as the price at time $t=0$,or $P_{2}=P_{0}=\lambda V_{h}+(1-\lambda) V_{\ell}$. At the other extreme, under strict liability, the damage payment is $L_{0}=\frac{\lambda_{0}}{1+\lambda_{0}}\left(V_{h}-V_{\ell}\right)$. Prices in this case are $P_{3}\left(V_{\ell}, s_{h}\right)=V_{\ell}+\frac{\lambda_{0}}{1+\lambda_{0}}\left(V_{h}-V_{\ell}\right)$ and $P_{2}\left(s_{h}\right)=$ $V_{\ell}+\frac{2 \lambda_{0}}{1+\lambda_{0}}\left(V_{h}-V_{\ell}\right)$. With a perfectly strict liability regime, due to the liability payment, both the short-term price, $P_{2}\left(s_{h}\right)$, and the terminal price, $P_{3}\left(V_{\ell}, s_{h}\right)$, are higher than when there is no liability.

Turning to the equilibrium audit quality, the auditor's first order condition is as in (3), where $E\left(L \mid V_{\ell}, s_{h}\right)=L_{0}$. In equilibrium, the conjecture about audit quality must be correct, or $\hat{a}=a_{0}^{*}$, where $a_{0}^{*}$ is the equilibrium audit effort with no informed trading.

Proposition 1 When there is no informed trading, i.e., $\rho=0$, an equilibrium exists in which the auditor chooses audit quality, $a_{0}^{*}$, which is interior, $a_{0}^{*} \in(0,1)$, when $c<c_{0}$, and otherwise is $a_{0}^{*}=0$. Market prices are given by (5), (8), and (6). Specifically, 
i. Audit quality is

$$
a_{0}^{*}=1-\frac{\lambda(1+\beta)}{(1-\lambda)\left[\frac{\lambda \beta}{c}\left(V_{h}-V_{\ell}\right)-1\right]}, \text { forc } \in\left(0, c_{0}\right) ; \text { otherwise, } a_{0}^{*}=0
$$

$$
\text { where } c_{0} \equiv \frac{\beta \lambda(1-\lambda)\left(V_{h}-V_{\ell}\right)}{1+\beta \lambda} \text {. }
$$

ii. Market prices when the audit signal is high are:

$$
\begin{aligned}
& P_{2}\left(s_{h}\right)=V_{\ell}+\frac{\lambda(1+\beta)\left(V_{h}-V_{\ell}\right)}{\lambda(1+\beta)+(1-\lambda)\left(1-a_{0}^{*}\right)}, P_{3}\left(V_{\ell}, s_{h}\right)=V_{\ell}+\frac{\beta \lambda\left(V_{h}-V_{\ell}\right)}{\lambda(1+\beta)+(1-\lambda)\left(1-a_{0}^{*}\right)}, \\
& \text { and } P_{3}\left(V_{h}, s_{h}\right)=V_{h} .
\end{aligned}
$$

In equilibrium, audit quality could either be an interior or a corner solution. In the latter case, the auditor does not provide any audit quality, i.e., audit quality is zero and the audit signal contains no information. Whether the auditor chooses an interior level of audit quality depends on whether the cost of auditing is sufficiently low, in relative terms. In particular, the interior equilibrium audit quality, in which the auditor chooses a strictly positive level of audit quality, is feasible for a sufficiently low level of auditing cost, $c<c_{0}$.

Next we consider the effect of the legal liability regime on audit quality.

Corollary 1 The stricter the legal liability regime, i.e., as $\beta$, increases, the higher is the interior equilibrium level of audit quality.

With no informed trading, market prices do not depend on order flow, but only depend on the audit signal. The strictness of the legal liability regime, $\beta$, affects not only the likelihood that the auditor must make a damage payment, but also the payment. As the strictness of the legal liability regime, $\beta$, increases, the likelihood that the auditor will make a payment to shareholders increases, but the damage payment, $L_{0}$, decreases. Combining the two effects, with a stricter liability regime, the expected damage payment to shareholders is higher.

\section{Informed Trading and Audit Quality}

\subsection{Informed Trading}

In this section we assume that the strategic trader may have perfect information about the firm's value, i.e., $\rho>0$. We consider a discrete version of the classic Kyle (1985) model (Maug, 
1998; Bernhardt et al., 1995) in which the market maker cannot always (perfectly) identify the strategic trader's informed trading by observing the order flow.

Following the release of a high audit signal, $s_{h}$, the strategic trader will either buy or sell $\Delta$ shares based on her private signal, $\omega$. Optimal trading following the high audit signal, $s_{h}$, implies that $r(\omega)=\Delta$, i.e., the strategic trader purchases shares, if $E\left(P_{2} \mid s_{h}, \Delta\right) \leq E\left(P_{3} \mid s_{h}, \omega\right)$, and sells $\Delta$ shares otherwise, i.e., if $E\left(P_{2} \mid s_{h},-\Delta\right) \geq E\left(P_{3} \mid s_{h}, \omega\right)$. We will establish an equilibrium in which the informed, strategic trader buys shares when she is endowed with a favorable signal, sells shares when she is endowed with an unfavorable signal, and does not trade when she is uninformed. Thus, we are looking for an equilibrium to support the trading behavior (following the realization of auditor signal $\left.s_{h}\right)$ :

$$
r(\omega)=\left\{\begin{array}{ll}
\Delta \text { (buy), } & \text { if } \omega=v_{h} \\
-\Delta \text { (sell), } & \text { if } \omega=v_{\ell}
\end{array}, r(\omega)=0 \text { (hold) when } \omega=\phi .\right.
$$

This implies the following possible levels of order flow when the strategic trader is informed, i.e., $\Phi=1:$

$$
\left.F\right|_{r=\Delta}=\left\{\begin{array}{cc}
2 \Delta & (q=\Delta) \text { w.p. } \theta \\
0 & (q=-\Delta) 1-\theta
\end{array},\left.F\right|_{r=-\Delta}=\left\{\begin{array}{cc}
0 & (q=\Delta) \text { w.p. } \quad \theta \\
-2 \Delta & (q=-\Delta) 1-\theta
\end{array}\right.\right.
$$

And, the following two possible levels of order flow when the strategic trader is uninformed, i.e., $\Phi=0$ :

$$
\left.F\right|_{r=0}=\left\{\begin{array}{cc}
\Delta & (q=\Delta) \text { w.p. } \theta \\
-\Delta & (q=-\Delta) 1-\theta
\end{array}\right.
$$

The market maker faces uncertainty regarding the level of trading by the strategic trader only when order flow is intermediate, i.e., $F=0$. Whenever $F=-2 \Delta(2 \Delta)$ it is clear that the strategic trader sold (bought) shares. When the order flow is intermediate, $F=0$, the market maker will use this order flow information together with her beliefs regarding the audit quality and the strategic trader's trading strategy. Finally, when the order flow satisfies $F=\Delta$ or $F=-\Delta$, then the market maker infers that the strategic trader did not trade. Note that due to our structure, the order flow's information content does not relate to the size of the liquidity shock, $\Delta$, but rather to the uncertainty associated with the shock as determined by $\theta$.

The market maker sets short term prices $P_{2}$ based on the auditor's signal, $s$, and the realized order flow, $F$, while terminal prices, $P_{3}$, are also conditional on the publicly observable value, $v$. 
Prices are set to yield zero profits to the competitive market maker:

$$
P_{3}(V, s, F)=E(V+\beta L \mid s, F) \text {, and } P_{2}(s, F)=E\left(P_{3}(V, s, F) \mid s, F\right) .
$$

In the previous section, we determined short term prices based on the audit signal when the strategic trader is uninformed. Now we consider short term prices when the strategic investor is informed, i.e., order flow can be of one of the following levels: $F=-2 \Delta, 0,2 \Delta$. Noteworthy, it is possible that the auditor makes no liability payment, even in the case of a mistaken audit signal. As discussed earlier, when the order flow is high, $F=2 \Delta$, it is clear that the strategic trader bought shares and the firm's value is high, $v_{h}$. In this case, no liability damage payment is due and the short term price in period $t=2$ reflects the firm's value. Similarly, when the order flow is low, $F=-2 \Delta$, the strategic trader sold shares and the firm's value is low, $v_{\ell}$. In both of these cases, $F=-2 \Delta, 2 \Delta$, prices reflect fundamentals in a timely fashion, at $t=2$, and investors do not incur losses upon the realization of the true firm output. Thus, for high and low order flow, $F=-2 \Delta$, $2 \Delta$, the market maker sets prices,

$$
\begin{aligned}
P_{2}\left(s_{h}, F=-2 \Delta\right) & =P_{3}\left(s_{h}, F=-2 \Delta, V_{\ell}\right)=V_{\ell} \\
P_{2}\left(s_{h}, F=2 \Delta\right) & =P_{3}\left(s_{h}, F=2 \Delta, V_{h}\right)=V_{h} .
\end{aligned}
$$

Put differently, due to informed trading, it is possible that even if the audit signal is high when the firm's value turns out to be low, market prices respond with a downward movement - that is, prices accurately reflect fundamentals, eliminating the auditor's liability.

Following an intermediate order flow, $F=0$, the market maker weighs the noise in the auditor's signal. At time $t=2$ the market price given the conjectured level of audit quality, $\hat{a}$, is,

$$
\begin{aligned}
P_{2}\left(s_{h}, F\right. & =0)=\lambda_{1} P_{3}\left(V_{h}, s_{h}, F=0\right)+\left(1-\lambda_{1}\right) P_{3}\left(V_{\ell}, s_{h}, F=0\right), \\
\text { where } \lambda_{1} & \equiv \operatorname{Pr}\left(V_{h} \mid s_{h}, F=0\right)=\frac{\lambda(1-\theta)}{\lambda(1-\theta)+(1-\lambda) \theta(1-\hat{a})} .
\end{aligned}
$$

Then, the consequent market prices and auditor liability when the strategic trader is informed, are,

$$
\begin{aligned}
P_{2}\left(s_{h}, F=0\right) & =V_{\ell}+\frac{(1+\beta) \lambda_{1}\left(V_{h}-V_{\ell}\right)}{1+\beta \lambda_{1}}, P_{3}\left(V_{\ell}, s_{h}, F=0\right)=V_{\ell}+\frac{\beta \lambda_{1}\left(V_{h}-V_{\ell}\right)}{1+\beta \lambda_{1}} \\
L_{1} & =L\left(V_{\ell}, s_{h}, F=0\right)=\frac{\lambda_{1}\left(V_{h}-V_{\ell}\right)}{1+\beta \lambda_{1}}
\end{aligned}
$$


In equilibrium, the auditor chooses audit quality given the expected liability, $E\left(L \mid V_{\ell}, s_{h}\right)$, which is only incurred when the audit report is high and the firm value is low and depends on whether the strategic trader is informed. If the strategic trader is uninformed, which occurs with probability $(1-\rho)$, the auditor's liability in the event of audit failure is $L_{0}$. If the strategic trader is informed, the auditor's liability in the event of audit failure is $L_{1}$, but is incurred only when order flow is intermediate, or $F=0$. When the firm's value is low, the informed trader sells, and order flow is intermediate only when the liquidity trader buys, which occurs with probability $\theta$. When order flow is low, or $F=-2 \Delta$, then, as previously discussed, the market maker infers the strategic trader's information about firm value, and sets the price accordingly, implying that there is no shareholder loss and no auditor liability. Thus, the auditor's expected liability is,

$$
E\left(L \mid V_{\ell}, s_{h}\right)=(1-\rho) L_{0}+\rho \theta L_{1}
$$

The market maker sets prices taking into account the conjectured level of audit quality. This means that the liability that depends on the price decrease following audit failure also depends on the conjectured level of audit quality. By substituting the values for $\lambda_{0}$ and $\lambda_{1}$ in $L_{0}$ and $L_{1}$, the auditor's liability when the strategic trader is uninformed and when he is informed can be restated as:

$$
E\left(L \mid V_{\ell}, s_{h}\right)=\frac{(1-\rho) \lambda\left(V_{h}-V_{\ell}\right)}{\lambda(1+\beta)+(1-\lambda)(1-\hat{a})}+\frac{\rho \lambda \theta(1-\theta)\left(V_{h}-V_{\ell}\right)}{\lambda(1+\beta)(1-\theta)+(1-\lambda) \theta(1-\hat{a})} .
$$

For a conjectured level of audit quality, the expected liability with informed trading is lower than if there is no informed trading, i.e., $\theta L_{1}<L_{0}$. This is because the auditor does not always incur liability damages in the event of audit failure when the strategic trader is informed. When the firm's value is low, $v_{\ell}$, and the strategic trader is informed, the short-term price after a high audit signal $P_{2}\left(s_{h}, F\right)$ depends on the order flow. If the order flow is low, then the short-term price reflects the firm's low value, $P_{2}\left(s_{h}, F=-2 \Delta\right)=P_{3}\left(s_{h}, F=-2 \Delta, V_{\ell}\right)=V_{\ell}$, and there is no auditor liability. When the strategic trader is uninformed, if the audit signal is high and the firm's value is low, the auditor will always incur a liability because the short-term price is higher than the firm's value.

The effect of the strictness of the legal liability regime, $\beta$, on the short-term and the terminal market prices for a conjectured level of audit quality, $\hat{a}$, is similar to when there is no informed trading. This is because with no liability, when $\beta=0$, audit quality is zero, and there is no change 
in the beliefs about the firm's value at time $t=2$. However, with a perfectly strict legal liability regime, i.e., $\beta=1$, and if the strategic trader is informed, the damage payment is $L_{1}=\frac{\lambda_{1}\left(V_{h}-V_{\ell}\right)}{1+\lambda_{1}}$. In this case, the short-term price when order flow is intermediate is $P_{2}\left(s_{h}, F=0\right)=V_{\ell}+\frac{2 \lambda_{1}}{1+\lambda_{1}}\left(V_{h}-V_{\ell}\right)$ and the terminal price is $P_{3}\left(V_{\ell}, s_{h}, F=0\right)=V_{\ell}+\frac{\lambda_{1}}{1+\lambda_{1}}\left(V_{h}-V_{\ell}\right)$. Because of the liability payment, both the short-term price, $P_{2}\left(s_{h}\right)$, and the terminal price, $P_{3}\left(V_{\ell}, s_{h}\right)$, are higher than when there is no liability.

Next, we analyze the Bayesian equilibrium, in which all players are optimizing, given their consistent beliefs about the other player's strategies. In any equilibrium, the auditor chooses audit quality, $a^{*}$ that satisfies (3), the strategic investor trades according to (10), prices are set by the market maker to satisfy are given by (11), and the audit fee is competitively set at (4). We summarize the conditions derived above that comprise an equilibrium in the following proposition, where $a^{*}$ and $c_{1}$ are defined in the proof in the Appendix.

Proposition 2 When there is the possibility of informed trading, i.e., $\rho \in(0,1)$, an equilibrium exists in which the auditor chooses audit quality, $a^{*}$, which is interior, $a^{*} \in(0,1)$, when $c<c_{1}$, and otherwise is $a^{*}=0$. Market prices when the audit signal is high and the strategic trader is uninformed, which occurs with probability $(1-\rho)$, are as in Proposition 1, and when the strategic trader is informed, which occurs with probability $\rho$, are given by (12) and (14). Specifically,

i. Audit quality satisfies

$$
a^{*}=1-\frac{c}{(1-\lambda) \beta\left[\rho \theta L_{1}\left(a^{*}\right)+(1-\rho) L_{0}\left(a^{*}\right)\right]} \text { for } c \in\left(0, c_{1}\right) ; \text { otherwise, } a^{*}=0
$$

ii. Market prices when the audit signal is high and order flow is intermediate are:

$$
\begin{aligned}
& P_{2}\left(s_{h}, F=0\right)=V_{\ell}+\frac{\lambda(1+\beta)(1-\theta)\left(V_{h}-V_{\ell}\right)}{\lambda(1+\beta)(1-\theta)+(1-\lambda) \theta\left(1-a^{*}\right)}, \text { and } \\
& P_{3}\left(s_{h}, F=0, V_{\ell},\right)=V_{\ell}+\frac{\lambda \beta(1+\beta)(1-\theta)\left(V_{h}-V_{\ell}\right)}{\lambda(1+\beta)(1-\theta)+(1-\lambda) \theta\left(1-a^{*}\right)} .
\end{aligned}
$$

Similar to the case with no informed trading, the equilibrium audit quality for a given level of informed trading could either be an interior or a corner solution, depending on the cost of auditing, c. With a corner solution, audit quality is zero and the auditor's signal contains no information. The lower the cost of auditing, $c$, the higher is the equilibrium level of audit quality. This means that if the cost of auditing is not too high, the interior equilibrium audit quality, in which the auditor chooses a strictly positive level of audit quality, is feasible

Next we consider the relation among audit quality, the strictness of the legal liability regime, 
the likelihood of informed trading, and uncertainty regarding the liquidity shock.

Corollary 2 When there is the possibility of informed trading, i.e., $\rho \in(0,1)$, the equilibrium audit quality is increasing in the strictness of the legal liability regime, $\beta$, decreasing in the likelihood of informed trading, $\rho$, and hump-shaped in the likelihood of the liquidity shock, $\theta$.

Just like with no informed trading, the stricter the legal liability regime, i.e., as $\beta$, increases, the higher is the interior equilibrium level of audit quality. The strictness of the legal liability regime, $\beta$, affects not only the likelihood that the auditor must make a damage payment, but also the payment. As the strictness of the legal liability regime, $\beta$, increases, the likelihood that the auditor will make a payment to shareholders increases, but the expected damage payment, $(1-\rho) L_{0}+\rho \theta L_{1}$, decreases. Combining the two effects, with a stricter liability regime, the expected damage payment to shareholders is higher.

In addition, there is a negative relation between the likelihood that the strategic trader is informed and the equilibrium audit quality. Intuitively, informed trading brings prices closer to fundamentals at time $t=2$, and serves as a hedge for the auditor against the potential liability risk due to an over-statement. Put differently, as previously discussed, the expected liability of the auditor, conditional on an overstatement, is lower when there is informed trading, relative to when the strategic trader is uninformed, i.e., $\theta L_{1}<L_{0}$. Thus, in the case that $a^{*}$ is interior, a marginal increase in $\rho$ leads to a marginal decrease in the equilibrium audit quality.

Audit quality is also affected by the likelihood of the liquidity shock. As the level of uncertainty regarding the liquidity shock decreases (or $\theta$ is closer to 1 or 0 ), it is more difficult for the strategic trader to hide her trades and, consequently, prices are closer to fundamentals. Again, this provides a hedge to the auditor against possible overstatement - as such overstatements inflate prices to a lesser extent, on average. This, in turn, lowers the auditor's expected liability and relaxes the incentives for audit quality. Of course, this requires some degree of informed trading, i.e., $\rho>0$, because in the benchmark case of $\rho=0$ there is no relation between the distribution of the liquidity shock and audit quality. Figure 2 illustrates this relationship between audit quality and the likelihood of the liquidity shock for both a high level of informed trading and a low level of informed trading.

Insert Figure 2 here 


\subsection{Information Production}

Informed traders not only submit trading orders strategically to take advantage of mispricing, but also devote resources to produce information about the firm's value in anticipation of future possible gains from trade (Grossman and Stiglitz, 1980; Verrecchia, 1982; Kyle 1989). In this section, we allow the strategic trader to determine the degree of information acquisition endogenously through incentives that stem from future expected gains from trade. To the extent that properly prepared audited financial statements level-the-playing-field among all market participants, they offer some form of protection to uninformed traders from informed trading by more sophisticated investors with better information endowment. As before, the auditor optimizes her choice of audit quality based on her conjecture of the extent of information contained in prices. The goal of this section is to analyze the joint determination of these two strategic decisions together with consistent pricing by the competitive market maker. We assume that the level of audit quality, and the level of information production of the strategic trader, are simultaneously and privately chosen.

We assume that the strategic trader faces a convex cost of information production given by $-\kappa \ln (1-\rho)$ for $\kappa>0$ and $\rho \in(0,1)$. Overall, the strategic trader's expected payoff, $U^{S}$, is given by her gains from trade, $\pi^{\text {inf }}$, and information production costs,

$$
U^{S}=E \pi^{\mathrm{inf}}+\kappa \ln (1-\rho)
$$

The strategic investor's expected gains from trade can only occur when the strategic trader is informed, i.e., $\Phi=1$, and when there is residual uncertainty following the auditor's signal, i.e., $s=s_{h}$. As discussed earlier, when $\Phi=1$ the strategic investor purchases shares when $v=v_{h}$ and sells when $v=v_{\ell}$. However, for gains from trade to materialize, the order flow must be $F=0$; otherwise, when $F=2 \Delta$, or $-2 \Delta$, the market maker can perfectly infer the firm's fundamental value from the order flow. Thus, when the order flow is intermediate and the price is $P_{2}\left(s_{h}, F=0\right)$, the gain from buying the undervalued stock is $\pi^{\mathrm{inf}}=\Delta\left[P_{3}\left(V_{h}, s_{h}\right)-P_{2}\left(s_{h}, F=0\right)\right]$ and from selling the over-valued stock is $\pi^{\mathrm{inf}}=\Delta\left[P_{2}\left(s_{h}, F=0\right)-P_{3}\left(V_{\ell}, s_{h}, F=0\right)\right]$. Overall, the ex-ante gross expected gains from trade are given by,

$$
\begin{aligned}
E \pi^{\mathrm{inf}}= & \rho \Delta\left[\lambda(1-\theta)\left(P_{3}\left(V_{h}, s_{h}\right)-P_{2}\left(s_{h}, F=0\right)\right)\right. \\
& \left.+(1-\lambda) \theta(1-\hat{a})\left(P_{2}\left(s_{h}, F=0\right)-P_{3}\left(V_{\ell}, s_{h}, F=0\right)\right)\right]
\end{aligned}
$$


The optimal response, for any conjectured $\widehat{a}$ is given by the solution to the following first order condition,

$$
\rho(\hat{a})=\max \left(1-\frac{\kappa}{\Delta\left(V_{h}-V_{\ell}\right)} \frac{[\lambda(1+\beta)(1-\theta)+(1-\lambda) \theta(1-\hat{a})]}{2 \lambda(1-\lambda) \theta(1-\theta)(1-\hat{a})}, 0\right) .
$$

Lemma 1 Given conjectured level of audit quality, $\hat{a}$, the strategic trader's best response information production level $\rho(\hat{a})$ is given by (19). Moreover, $\rho(\hat{a})$ is decreasing in $\hat{a}$ and $\beta$, and is humped shaped in $\theta$.

It is important to note that the strategic trader will respond by producing less information to an increase in the level of audit quality chosen by the auditor. Thus, there is clear tradeoff in terms of market efficiency - audit quality and information production by the strategic investor are strategic substitutes. This implies that the strategic trader responds with more information production to lower conjectured audit quality, $\hat{a}$. Intuitively, higher audit quality results in a lower likelihood of the stock being mispriced, and therefore less possibility for the strategic trader to profit from informed trading (all else equal). Thus, as informed trading crowds-out, so to speak, audit quality (e.g., see Corollary 2), so does audit quality for information production efforts by the strategic trader.

Turning to the liability parameter $\beta$, the stricter the legal liability regime, the more shareholders anticipate (on average) to be compensated when the firm's value is low, $v_{\ell}$ and the audit signal is high, $s_{h}$, all else equal. This type of insurance reduces the potential for trading gains for the strategic investor. Thus, she responds to higher levels of $\beta$ with less information production, all else equal. Finally, the response $\rho(\hat{a})$ is non-monotonic in the likelihood of the liquidity shock, $\theta$. Intuitively, when there is more uncertainty regarding the liquidity shock (i.e., $\theta$ is intermediate), the strategic trader can better hide her trades and exploit her information advantage. Figure 3 depicts the response function $\rho(\hat{a})$ to illustrate the aforementioned properties.

Insert Figure 3 here.

Proposition 3 There exists an equilibrium $\left\langle a^{*}, \rho^{*}\right\rangle$ in which the strategic trader produces information $\rho^{*}$ that satisfies (19), the auditor chooses audit quality $a^{*}$ that satisfies (16), the expected liability upon overstatement by the auditor $E\left(L\left(s_{h}, v_{\ell}\right)\right)$ satisfies (15), and prices are given by (5) $-(14)$.

In order to focus the analysis on interior solutions, where both the auditor and the informed trader produce information, we restrict attention to sufficiently small costs $c$ and $\kappa$. In particular, 
the auditor will choose an interior level of audit quality provided that $a(\hat{\rho})>0$ when evaluated at the point $\hat{\rho}=1$. Furthermore, because the internal level of audit quality is bounded from above by $a_{0}^{*}$ given by $(9)$, it follows that $\rho$ is interior if $\rho(\hat{a})>0$ when evaluated at the point $\hat{a}=a_{0}^{*}$. This follows because there must be an odd number of solutions in order for the condition $\rho\left(a_{0}^{*}\right)>0$ to be satisfied and, as established in the proof of Proposition 3 there are at most two interior solutions to the equilibrium quadratic equation condition. Of course, when costs are higher, then corner solutions are possible, as is apparent in the subsequent figures.

Corollary 3 The equilibrium is unique and interior provided that $c \leq c_{2}$ and $\kappa<\kappa_{c}$, where

$$
c_{2} \equiv \frac{\theta(1-\theta)(1-\lambda) \lambda \beta\left(V_{h}-V_{\ell}\right)}{\lambda(1+\beta)(1-\theta)+\theta(1-\lambda)} \text { and } \kappa_{c} \equiv \frac{2 \lambda(1-\theta) \Delta\left(V_{h}-V_{\ell}\right)}{\frac{1-\theta}{\theta}\left(\frac{\lambda \beta}{c}\left(V_{h}-V_{\ell}\right)-1\right)+1}
$$

Having established the existence of a completely interior equilibrium, we turn to how the equilibrium $\left\langle a^{*}, \rho^{*}\right\rangle$ varies with the properties of the financial market, e.g., the distribution of liquidity trading $\theta$, and the properties of the regulatory system, captured by $\beta$.

Corollary 4 An increase in the strictness of the legal liability regime, $\beta$, increases the equilibrium interior audit quality, $a^{*}$, and decreases the equilibrium interior information production, $\rho^{*}$. Furthermore, both the equilibrium interior audit quality, $a^{*}$, and the equilibrium interior information production, $\rho^{*}$, are non-monotonic in the likelihood of the liquidity shock, $\theta$.

Several studies have demonstrated a positive link between the strictness of the regulatory system and audit quality. We also find this positive relation, i.e., as $\beta$ increases so does the equilibrium level of audit quality. However, this increase in $\beta$ also leads to a reduction in informed trading. One might view this as a desirable outcome from the perspective of the uninformed investors. That is, higher audit quality together with stricter legal liability, lead to less wealth extraction by the strategic trader. Figure 4 depicts the shift from one equilibrium outcome to another as the level of enforcement or strictness, $\beta$, increases. As one can notice, the response functions of the auditor and the strategic trader shift as a result of the shift in $\beta$. While the auditor responds with elevated levels of quality when the enforcement system is more strict, the strategic trader responds by allocating fewer resources to information production. Thus, overall, an upward shift in strictness leads to higher audit quality and less informed trading.

Insert Figure 4 here. 
Turning to the likelihood of the liquidity shock, $\theta$, it influences both the incentives for audit quality and the incentives for information production by the strategic trader. When examined separately, intermediate values of $\theta$ encourage the auditor to exert more effort in audit quality and also encourage the strategic trader to produce more information, relative to extreme levels, i.e., when $\theta$ is close to 0 or 1 . Interestingly, in equilibrium, the level of informed trading is higher and the level of audit quality is lower for intermediate values of $\theta$. Intuitively, because the strategic trader finds it optimal to scale down information production when the liquidity trading is less uncertain, i.e., when $\theta$ is close to 0 or 1 , this encourages higher audit quality. Actually, the audit quality approaches the maximum $a_{0}^{*}$ when $\theta \sim 0$ or $\theta \sim 1$, i.e., when $\rho^{*}$ is 0 . For intermediate values of $\theta$, however, there is a strictly positive level of informed trading, i.e., $\rho^{*}>0$, and the level of audit quality is lower. Figure 5 depicts the equilibrium levels $\left\langle a^{*}, \rho^{*}\right\rangle$ as a function of the likelihood of the liquidity shock.

Insert Figure 5 here

\subsection{Real Investment}

In addition to the firm's assets in place that we considered earlier, i.e., $v \in\left\{v_{\ell}, v_{h}\right\}$, where $0 \leq v_{\ell}<v_{h}$, we now assume that the firm is also endowed with a growth opportunity. This requires an investment, $I$, and yields a stochastic payoff of $\pi>0$ when the productivity state is high and when $v=v_{h}$ and zero otherwise. The growth opportunity is in the same line of business, e.g., a corporate expansion of operations geographically, that is perfectly correlated with the value of assets in place. That is, in the high state of the world and when $v=v_{h}$, the growth opportunity is $g=\pi-I>0$, and in the low state of the world when $v=v_{\ell}$, the growth option has net present value of $-I$. The capital investment of $I$ in firm growth takes place after the auditor's signal is made public and after trading takes place, but before the state of the world becomes publicly observable. We assume that the investment is risk-free, which means that the firm repays the investor the investment of $I$, regardless of the firm's productivity state. This implies that when the firm's productivity state is low and $v=v_{\ell}$, the investor has no loss and therefore does not sue the auditor, even if the audit signal is high. ${ }^{7}$

Because the true state of the world is not publicly observable at the time of investment, information contained in market prices might potentially be useful in the process of efficiently allocating

\footnotetext{
${ }^{7}$ By assuming that the investment is risk-free, we abstract away from asset substitution problems.
} 
investment capital. We assume that a rational, profit maximizing investor or capital provider makes the investment decision, which is denoted by $\psi \in\{0,1\}$, where $\psi=1$ means investment takes place. The investor finds it optimal to invest whenever the expected net present value of the growth option is positive, conditional on the realized audit signal, $s$, and order flow, $F$. We can, without loss of generality, restrict attention to the pair $\langle s, F\rangle$ because market prices perfectly correspond to the realization of $\langle s, F\rangle$ in equilibrium and are in this sense redundant. We use the notation above to define the strategy $\psi(s, F)$ of the investor as the function $\psi: \mathbf{R}^{2} \rightarrow\{0,1\}$.

\subsubsection{No Informed Trading}

We start with the investor's equilibrium strategy when there is no informed trading, i.e., $\rho=0$, which means that the investment decision only depends on the audit signal, or $\psi(s)$. If the audit signal is low, $s_{\ell}$ then, with certainty the firm's state of productivity is low and $v=v_{\ell}$. This means that the growth opportunity has a negative value and investors will optimally choose not to invest, i.e., $\psi\left(s_{\ell}\right)=0$. If the audit signal is high, $s_{h}$, there is uncertainty regarding the firm's true state of productivity. Given a high audit signal, $s_{h}$, and conjecture of audit quality, $\hat{a}$, the likelihood that the true state of productivity is high is $\operatorname{Pr}\left(v_{h} \mid s_{h}\right)=\lambda_{0} \equiv \frac{\lambda}{\lambda+(1-\lambda)(1-\hat{a})}$ and, therefore, investment is optimal, i.e., i.e., $\psi\left(s_{h}\right)=1$, when,

$$
\pi \operatorname{Pr}\left(v_{h} \mid s_{h}\right)-I \geq 0 \Leftrightarrow \pi \geq \pi_{0} \equiv \frac{[\lambda+(1-\lambda)(1-\hat{a})] I}{\lambda}
$$

In the following, we analyze the case where $\pi \geq \pi_{0}$, which means that the investor uses the audit signal to make his investment decision. With the investment strategy of $\psi\left(s_{h}\right)=1$ and $\psi\left(s_{\ell}\right)=0$, the growth opportunity affects both short-term and terminal market prices. After the firm's productivity state is observed, terminal prices are $P_{3}\left(V_{h}, s_{h}\right)=V_{h}+\pi-I, P_{3}\left(V_{\ell}, s_{h}\right)=$ $V_{\ell}-I+\beta L_{0}^{I n v}$, and $P_{3}\left(V_{\ell}, s_{\ell}\right)=V_{\ell}$. With investment given the high audit signal, $s_{h}$ the price in the high state increases by $\pi-I$, but the decrease in value in the low state is $-I$. In other words, the value differential given the high audit signal, $V_{h}-V_{\ell}$, increases by $\pi$. Thus, short term prices are $P_{2}\left(s_{h}\right)=\lambda_{0}\left[V_{h}-V_{\ell}+\pi+\beta L_{0}\right]$ and $P_{2}\left(s_{\ell}\right)=V_{\ell}$. Using the same analysis as in the previous section with no investment, the auditor's liability payment is:

$$
L_{0}^{I n v}=\frac{\lambda_{0}\left(V_{h}-V_{\ell}+\pi\right)}{1+\beta \lambda_{0}}=\frac{\lambda\left(V_{h}-V_{\ell}+\pi\right)}{\lambda(1+\beta)+(1-\lambda)(1-\hat{a})} .
$$

Substituting for $L_{0}^{I n v}$ in the second period price given a high audit signal, $P_{2}\left(s_{h}\right)$, yields: 


$$
P_{2}\left(s_{h}\right)=V_{\ell}-I+\frac{(1+\beta) \lambda_{0}}{1+\beta \lambda_{0}}\left(V_{h}-V_{\ell}+\pi\right) .
$$

The auditor must take into account the effect of investment on the market prices when choosing audit quality because of the impact investment has on the auditor's liability payment. The auditor's first order condition is as in (3), where $E\left(L \mid V_{\ell}, s_{h}\right)=L_{0}^{I n v}$. Specifically, the interior equilibrium audit quality with no informed trading, i.e., $\rho=0$, is:

$$
\begin{aligned}
a_{0}^{\text {Inv* }} & =1-\frac{\lambda(1+\beta)}{(1-\lambda)\left[\frac{\lambda \beta}{c}\left(V_{h}-V_{\ell}+\pi\right)-1\right]} \text { if } c \in\left(0, c_{0}^{I n v}\right), \\
\text { where } c_{0}^{I n v} & =\frac{\beta \lambda(1-\lambda)\left(V_{h}-V_{\ell}+\pi\right)}{1+\beta \lambda} .
\end{aligned}
$$

Because the liability payment is higher with investment when $\pi \geq \pi_{0}$ for a conjectured $\hat{a}$, i.e., $L_{0}^{I n v}>L_{0}$, the equilibrium audit quality is higher than without the growth opportunity, i.e., $a_{0}^{I n v *} \geq a_{0}^{*}$.

Next, we turn to investment efficiency when there is no informed trading. If the investor is informed about the firm's productivity state prior to making the investment decision, then clearly the efficient investment strategy would be to only invest in the high state of the world, when $v=v_{h}$, and the value of the growth option is $\lambda(\pi-I)$. However, with no information about the firm's productivity state and only using the audit signal, the value of the growth option with no informed trading and $\pi \geq \pi_{0}$ is:

$$
V G_{0}=\lambda(\pi-I)-(1-\lambda)\left(1-a_{0}^{I n v *}\right) I
$$

With an imperfect audit signal, the investor sometimes overinvests, and invests in a firm with low productivity. Thus, when the audit signal is high, $s=s_{h}$, and the firm's value is low, $v=v_{\ell}$, the firm loses the investment, $I$, and the expected investment loss is $(1-\lambda)\left(1-a_{0}^{I n v *}\right) I$.

The following proposition states the effect of an increase in the strictness of the legal liability regime on the value of the growth option with no informed trading.

Proposition 4 With no informed trading, an increase in the strictness of the legal liability regime increases the value of the growth option for a high growth firm when audit quality is interior; otherwise, an increase in the strictness of the legal liability regime has no effect. Specifically, with $\pi \geq \pi_{0}$ and $c<c_{0}^{\text {Inv }}$, if $\beta$ increases, then $V G_{0}$ decreases.

An increase in the strictness of the legal liability regime, or an increase in $\beta$, causes the equi- 
librium interior audit quality to increase. This means that a high audit signal is more informative about the firm's value, and given a high audit signal, the likelihood that the firm's productivity state is low is lower. With no informed trading, this means that investment efficiency is higher because the investor only uses the audit signal to make the investment decision. With higher audit quality, the investor is less likely to overinvest.

\subsubsection{Informed Trading}

We now consider how informed trading affects investment efficiency. When the strategic trader may be informed, i.e., $\rho \in(0,1)$, the investor's strategy can depend on both the audit signal and the order flow, i.e., $\psi(s, F)$. As with no informed trading, a low audit signal, $s_{\ell}$, indicates with certainty that the firm's productivity is low, implying that the growth opportunity has a negative value. This means that investors will optimally choose not to invest, i.e., $\psi\left(s_{\ell}, F\right)=0$, for any order flow $F$. Similarly, investment will not take place when the audit signal is high, $s_{h}$, and the order flow is low, $F=-2 \Delta$, because this event also reflects the low state of the world with certainty, i.e., $\psi\left(s_{h},-2 \Delta\right)=0$. At the other extreme, when the audit signal is high and the order flow is high, $F=2 \Delta$, then the firm's productivity is high with certainty, and it is optimal for investment to take place, i.e., $\psi\left(s_{h}, 2 \Delta\right)=1$. This implies that second period market prices, in these cases where the auditor's signal and/or the order flow reveal precisely the true state of the world, are given by $P_{2}\left(s_{h}, F=2 \Delta\right)=V_{h}+\pi-I$, and $P_{2}\left(s_{h}, F=-2 \Delta\right)=P_{2}\left(s_{\ell}, F\right)=V_{\ell}$.

However, there is uncertainty about the true state of productivity following a high audit signal, $s_{h}$, and when the order flow is intermediate, $F=0$, which indicates that the strategic trader is informed and which occurs with probability $\rho$. An order flow of either $F=-\Delta$, or $F=\Delta$ indicates that the strategic trader is uninformed, which occurs with probability $(1-\rho)$. Given the analysis above with no informed trading, we next focus on the case when the strategic trader is informed. With an intermediate order flow, $F=0$, and conjecture $\hat{a}$, the likelihood that the true state of productivity is high is $\operatorname{Pr}\left(v=v_{h} \mid s_{h}, F=0\right)=\lambda_{1} \equiv \frac{\lambda(1-\theta)}{\lambda(1-\theta)+(1-\lambda)(1-\hat{a}) \theta}$ and, therefore, investment is optimal when,

$$
\pi \operatorname{Pr}\left(v=v_{h} \mid s_{h}, F=0\right)-I \geq 0 \Leftrightarrow \pi \geq \pi_{1} \equiv \frac{[\lambda(1-\theta)+(1-\lambda) \theta(1-\hat{a})] I}{\lambda(1-\theta)} .
$$

We first focus on the case where $\pi \geq \pi_{1}$, which means that the investor uses the audit signal to make his investment decision. With a high audit signal and when the order flow is intermediate, the 
investor's strategy affects both short-term and terminal market prices as follows. After the firm's productivity state is observed, terminal prices are $P_{3}\left(V_{h}, s_{h}, F=0\right)=V_{h}+\pi-I$, and $P_{3}\left(V_{\ell}, s_{h}, F=\right.$ $0)=V_{\ell}-I+\beta L_{1}^{I n v}$. The second-period price is $P_{2}\left(s_{h}, F=0\right)=\lambda_{1}\left[V_{h}-V_{\ell}+\pi+\beta L_{1}^{I n v}\right]$. Using the same analysis as in the previous section with no informed trading, the auditor's liability payment is:

$$
L_{1}^{I n v}=\frac{\lambda_{1}\left(V_{h}-V_{\ell}+\pi\right)}{1+\beta \lambda_{1}}=\frac{\lambda(1-\theta)\left(V_{h}-V_{\ell}+\pi\right)}{\lambda(1+\beta)(1-\theta)+(1-\lambda) \theta(1-\hat{a})} .
$$

Substituting for $L_{1}^{I n v}$ in the second period price given a high audit signal and intermediate order flow yields:

$$
P_{2}\left(s_{h}, F=0\right)=V_{\ell}-I+\frac{(1+\beta) \lambda_{1}}{1+\beta \lambda_{1}}\left(V_{h}-V_{\ell}+\pi\right) .
$$

Now that we have established the optimal investment action of the capital provider, we now turn to the response function of the strategic trader $\rho(\hat{a})$. In other words, we define the response as a function of the auditor's choice of audit quality, $a$ and also conjectured by capital market participants. Notice that the strategic trader's payoff does not depend on prices that follow order flow $F=\Delta,-\Delta$ (i.e., when she is uninformed), or $F=2 \Delta,-2 \Delta$ (i.e., her private information is completely revealed). Instead, her payoff stems from the prices that follow $F=0$ order flow only. Thus, the response for $\pi \geq \pi_{1}$ will incorporate the action of investment and its implications for firm value and the prices set by the market maker. Actually, this increases the value in the high state to be $V_{h}+\pi-I$ and decreases the value in the low state to be $V_{\ell}-I$. In other words, the value differential, $V_{h}-V_{\ell}$ increases by $\pi$. The strategic trader's response function is given as follows:

$$
\begin{gathered}
\rho^{I n v *}(\hat{a})=\max \left(1-\frac{\kappa}{\Delta\left(V_{h}-V_{\ell}+\pi\right)} \frac{\lambda(1+\beta)(1-\theta)+(1-\lambda) \theta(1-\hat{a})}{2 \lambda(1-\lambda) \theta(1-\theta)(1-\hat{a})}, 0\right) \text { for } \pi \geq \pi_{1}, \text { and } \kappa \in\left(0, \kappa_{c}^{\text {Inv }}\right), \\
\text { where } \kappa_{c}^{\text {Inv }} \equiv \frac{\left.2 \lambda(1-\theta) \Delta\left(V_{h}-V_{\ell}+\pi\right)\right)}{\frac{1-\theta}{\theta}\left(\frac{\lambda \beta}{c}\left(V_{h}-V_{\ell}\right)-1\right)+1}
\end{gathered}
$$

Turning to the auditor, we consider her response to a conjectured information production level, $\hat{\rho}$, or, $a(\widehat{\rho})$. Audit quality satisfies

$$
\begin{gathered}
a^{I n v *}(\widehat{\rho})=1-\frac{c}{(1-\lambda) \beta\left[\widehat{\rho} \theta L_{1}^{\operatorname{Inv}}\left(a^{*}\right)+(1-\widehat{\rho}) L_{0}^{I n v}\left(a^{*}\right)\right]} \text { for } c \in\left(0, c_{1}^{\operatorname{Inv}}\right) \text { and } \pi \geq \operatorname{Max}\left\{\pi_{1}, \pi_{0}\right\} \\
\text { where } c_{1}^{I n v} \equiv \frac{\theta(1-\theta)(1-\lambda) \lambda \beta\left(V_{h}-V_{\ell}+\pi\right)}{\lambda(1+\beta)(1-\theta)+\theta(1-\lambda)}
\end{gathered}
$$


We turn next to investment efficiency with the possibility of informed trading, depending on the level of the growth opportunity. As above with no informed trading, with the most efficient investment, the value of the growth option is $\lambda(\pi-I)$. With a high growth opportunity, i.e., $\pi \geq \operatorname{Max}\left\{\pi_{1}, \pi_{0}\right\}$, investment occurs when the strategic trader is informed and order flow is not low, $F=\{2 \Delta, 0\}$ and when the strategic trader is uninformed and the audit signal is high, or when $s=s_{h}$ and $F=\{\Delta,-\Delta\}$. Overall, the value of the growth option in a high growth firm is:

$$
V G_{1}^{H i g h}=\rho^{I n v *}\left[\lambda(\pi-I)-(1-\lambda) \theta\left(1-a^{I n v *}\right) I\right]+\left(1-\rho^{I n v *}\right)\left[\lambda(\pi-I)-(1-\lambda)\left(1-a^{I n v *}\right) I\right]
$$

Investment inefficiency with a high growth opportunity is only due to overinvestment, which occurs when the strategic trader is informed and uninformed. If the strategic trader is uninformed, the expected investment loss is as above with no informed trading. However, if the strategic trader is informed, overinvestment occurs when the order flow is intermediate and when the firm's productivity is low.

With a low growth opportunity, i.e., $\pi \leq \operatorname{Min}\left\{\pi_{1}, \pi_{0}\right\}$, investment occurs only when the strategic trader is informed and the order flow is high, $F=2 \Delta$, which means that with certainty, the firm's productivity state is high. In this case, the strategic trader's response function $\rho^{*}$, and audit quality, $a^{*}$, are as in the section without investment. The only investment inefficiency is due to underinvestment, i.e., not investing when the firm's productivity state is high. The value of the growth option in a low growth firm is:

$$
V G_{1}^{\text {Low }}=\rho^{*} \lambda \theta(\pi-I)
$$

With an intermediate growth opportunity, the optimal investment strategy depends on the likelihood of the liquidity shock, $\theta$. If the likelihood of the liquidity shock is high, i.e., $\theta>1 / 2$, then $\pi_{0}<\pi_{1}$, and an intermediate growth opportunity means that $\pi_{0} \leq \pi<\pi_{1}$. Then, the investor invests when the strategic trader is informed but only when the order flow is high, $F=2 \Delta$, and when the strategic trader is uninformed and the audit signal is high, or when $s=s_{h}$ and $F=\{\Delta,-\Delta\}$. In this case, the strategic trader's response function $\rho^{*}$, is the same as with no investment, but audit quality depends on the growth opportunity, i.e., $a^{I n v *}$. There is investment inefficiency is due to underinvestment when the strategic trader is informed and overinvestment when the strategic trader is uninformed. Overall, the value of the growth option in an intermediate growth firm, when 
the likelihood of the liquidity shock is high, is:

$$
V G_{1}^{\text {Interm } 1}=\rho^{*} \lambda \theta(\pi-I)+\left(1-\rho^{*}\right)\left[\lambda(\pi-I)-(1-\lambda)\left(1-a^{\text {Inv* }}\right) I\right]
$$

If the likelihood of the liquidity shock is low, i.e., $\theta<1 / 2$, then $\pi_{1}<\pi_{0}$, and an intermediate growth opportunity means that $\pi_{1} \leq \pi<\pi_{0}$. Then, the investor invests when the strategic trader is informed and the order flow is not low, i.e., $F=\{2 \Delta, 0\}$, but does not invest when the strategic trader is uninformed. This means that the strategic trader's response function depends on the growth opportunity, $\rho^{I n v *}$, but audit quality is the same as with no investment, i.e., $a^{*}$. Investment inefficiency is due to underinvestment when the strategic trader is uninformed and overinvestment when the strategic trader is informed. Overall, the value of the growth option in an intermediate growth firm, when the likelihood of the liquidity shock is low, is:

$$
V G_{1}^{\text {Interm } 2}=\rho^{I n v *}\left[\lambda(\pi-I)-(1-\lambda) \theta\left(1-a^{*}\right) I\right]
$$

The following proposition states the effect of an increase in the strictness of the legal liability regime on the value of the growth option with informed trading.

Proposition 5 With informed trading, an increase in the strictness of the legal liability regime can either increase or decrease the value of the firm's growth option, depending on the level of the growth option and whether audit quality is interior or at a minimum.

$i$. The value of the firm's growth option is decreasing in the strictness of the legal liability regime when the value of the growth option is low, or when the value of the growth option is not low and audit quality is at a minimum. Specifically, an increase in $\beta$ causes $V G_{1}^{\text {Low }}$ to decrease, and if $c>c_{1}^{\text {Inv }}$, then $V G_{1}^{\text {High }}, V G_{1}^{\text {Interm } 1}$, and $V G_{1}^{\text {Interm } 2}$ also decrease.

ii. The value of the firm's growth option is increasing in the strictness of the legal liability regime if the value of the growth option is intermediate, the likelihood of the liquidity shock is high, and audit quality is interior. Specifically, if $c \leq c_{1}^{\text {Inv }}$, then an increase in $\beta$ causes $V G_{1}^{\text {Interm } 1}$ to increase.

iii. The value of the firm's growth option can be increasing in the strictness of the legal liability regime if the value of the growth option is high or if it is intermediate and the likelihood of the liquidity shock is low, and audit quality is interior. Specifically, if $c \leq c_{1}^{\text {Inv }}$, then with an increase in $\beta, V G_{1}^{\text {Interm } 2}$ and $V G_{1}^{\text {High }}$ may either increase or decrease. 
When audit quality has no effect on investment, an increase in the strictness of the legal liability regime decreases the value of the growth option, as in Case (i) of Proposition 5. With a low growth option, i.e., $\pi \leq \operatorname{Min}\left\{\pi_{1}, \pi_{0}\right\}$, investment only occurs when the strategic investor is informed and order flow is high, but does not depend on audit quality. From Corollary 4, an increase in the strictness of the legal liability regime causes the informed trader's information production to decrease. Thus, with a low growth option, a stricter legal liability regime results in a lower likelihood that the strategic trader is informed and a lower value of the growth option. There is a similar effect when the level of the growth option is intermediate or high, and the audit cost is high. In these cases, the auditor supplies the minimum audit quality, which means that an increase in the strictness of the legal liability regime has no effect on audit quality, but only decreases the likelihood that the strategic trader is informed, and decreases the value of the growth option. Figure 6 shows the effect of the strictness of the legal liability regime, $\beta$, on the value of the growth option, equilibrium audit quality, and the strategic trader's equilibrium information production for low growth firms (Panels A and B) and for high growth firms (Panels C and D).

\section{Insert Figure 6 here}

Focusing on the interior equilibrium, both audit quality and informed trading affect investment when the value of the growth option is either intermediate or high, as in as in Cases (ii) and (iii) of Proposition 5. Stricter liability has two opposing effects due to higher audit quality and lower information production on the part of the strategic trader. With higher audit quality, the audit signal is less likely to mistakenly report a low value firm as a high value firm. Thus, for a given level of informed trading, stricter liability means a higher value of the growth option because of less overinvestment. When the strategic trader is informed, market prices are more informative about the firm's value, and investment efficiency is higher. However, stricter liability means less information production, and for a given level of audit quality, the value of the growth option is lower.

The impact of higher audit quality and less informed trading on the value of the growth option depends on the level of the growth option. When the value of the growth option is intermediate and the likelihood of liquidity is high, i.e., $\theta>1 / 2$ and $\pi_{0} \leq \pi<\pi_{1}$, the effect of higher audit quality dominates the effect of lower information production on the part of the strategic trader. This is because when the strategic trader is informed, investment only occurs when the order flow is high, and the firm's value is high with certainty; audit quality has no effect on investment unless 
the strategic trader is uninformed. When the value of the growth option is intermediate and the likelihood of liquidity is low, i.e., $\theta<1 / 2$ and $\pi_{1} \leq \pi<\pi_{0}$ or when the value of the growth option is high, $\pi \geq \operatorname{Max}\left\{\pi_{1}, \pi_{0}\right\}$, then there is a tradeoff between higher audit quality and less information production in the effect on the value of the growth option.

For example, with a high growth opportunity, i.e., $\pi \geq \operatorname{Max}\left\{\pi_{1}, \pi_{0}\right\}$, an increase in $\beta$ has the following effect on the value of the growth option:

$$
\frac{\partial V G_{1}^{H i g h}}{\partial \beta}=(1-\lambda)\left\{\frac{\partial \rho^{I n v *}}{\partial \beta}\left(1-a^{I n v *}\right)(1-\theta)+\frac{\partial a^{I n v *}}{\partial \beta}\left[\left(1-\rho^{I n v *}\right)+\rho^{I n v *} \theta\right]\right\} I
$$

The first term in the curly brackets in (31) is the effect of stricter liability on the value of the growth option due to the strategic trader's decreased information production, which is negative. In the case when the audit signal is high but the firm value is low, the benefit of an informed strategic trader is when the price indicates that the firm value is low, which occurs when the strategic trader and the liquidity trader sell their shares. The second term in the curly brackets in (31) is the effect of stricter liability on the investment loss due to higher audit quality, which is positive. The effect of higher audit quality depends on whether the strategic trader is informed or uninformed; when the strategic trader is informed and the firm value is low, higher audit quality is beneficial in reducing overinvestment. Combining these two effects yields an ambiguous result, which means that the value of the growth option may increase with a stricter legal liability regime.

\section{Conclusion}

In this paper, we study how informed, strategic trading affects the quality of a firm's audited financial report. We show that with an out of pocket damage payment in the event of a shareholder lawsuit due to audit failure, informed trading provides a hedge to the auditor against liability risk. With informed trading, prices are more informative about the firm's fundamental value, which decreases the auditor's out of pocket damage payment. Similarly, for higher audit quality, strategic traders respond with less informed trading, because the quality of the firm's financial report is higher, and prices are more informative. Our results highlight the importance of informed trading in understanding an auditor's incentive to provide high audit quality.

With more uncertainty about the liquidity trader's demand, prices are less informative about the firm's value, which affects informed trading as well as audit quality. In equilibrium, informed trading increases because the strategic trader is able to better profit from her information. Audit 
quality can increase or decrease, because of the interaction between less informative prices (and higher liability) and increased informed trading. Thus, the qualities of the efficiency of the market affects audit quality through the impact of informed trading, as well as the efficiency of market prices.

An increase in the strictness of the legal liability regime increases audit quality and the quality of a firm's audited financial report, due to higher expected legal liability, but it causes the strategic trader to devote fewer resources to producing information about firm value. The strictness of the auditor's legal liability regime also affects real investment in a firm's growth opportunity. When the firm has a low growth opportunity that requires a riskless investment or when audit quality is at a minimum, a stricter legal liability regime increases decreases the value of the growth opportunity, because with less informed trading, prices are not as informative.

The results have implications for regulators who are motivated to increase transparency and provide a level playing field for market participants. While informed trading allows for strategic traders to profit at the expense of uninformed market participants, prices are more informative about the firm's value, which lowers the auditor's out of pocket damage payment to shareholders in the event of audit failure. Stricter legal liability, which increases the likelihood that the auditor is found liable, can cause higher audit quality and less informed trading, which can result in a lower firm value. 


\section{Appendix}

Proof. Proposition 1: With no informed trading, substituting for $E\left(L \mid V_{\ell}, s_{h}\right)=\frac{\lambda\left(V_{h}-V_{\ell}\right)}{\lambda(1+\beta)+(1-\lambda)(1-\hat{a})}$ in the auditor's first order condition yields the interior solution,

$$
a_{0}^{*}=1-\frac{c\left[\lambda(1+\beta)+(1-\lambda)\left(1-a_{0}^{*}\right)\right]}{\beta \lambda(1-\lambda)\left(V_{h}-V_{\ell}\right)} .
$$

Rearranging, this is

$$
a_{0}^{*}=1-\frac{\lambda(1+\beta)}{(1-\lambda)\left[\frac{\lambda \beta}{c}\left(V_{h}-V_{\ell}\right)-1\right]} .
$$

The interior solution is only feasible if $1-\frac{\lambda(1+\beta)}{(1-\lambda)\left[\frac{\lambda \beta}{c}\left(V_{h}-V_{\ell}\right)-1\right]} \geq 0$, or if:

$$
c \leq c_{0}=\frac{\beta \lambda(1-\lambda)\left(V_{h}-V_{\ell}\right)}{1+\beta \lambda} .
$$

Proof. Corollary 1: With no informed trading, the interior equilibrium audit quality, $a_{0}^{*}=$ $1-\frac{\lambda(1+\beta)}{(1-\lambda)\left[\frac{\lambda \beta}{c}\left(V_{h}-V_{\ell}\right)-1\right]}$, for $c \in\left(0, c_{0}\right)$ is increasing in $\beta$ if $\frac{\partial a_{0}^{*}}{\partial \beta}>0$, where:

$$
\begin{aligned}
\frac{\partial a_{0}^{*}}{\partial \beta} & =-\lambda(1-\lambda)\left(\frac{\frac{\lambda \beta}{c}\left(V_{h}-V_{\ell}\right)-1-(1+\beta) \frac{\lambda}{c}\left(V_{h}-V_{\ell}\right)}{(1-\lambda)^{2}\left[\frac{\lambda \beta}{c}\left(V_{h}-V_{\ell}\right)-1\right]^{2}}\right) \\
& =-\lambda(1-\lambda)\left(\frac{-1-\frac{\lambda}{c}\left(V_{h}-V_{\ell}\right)}{(1-\lambda)^{2}\left[\frac{\lambda \beta}{c}\left(V_{h}-V_{\ell}\right)-1\right]^{2}}\right) .
\end{aligned}
$$

This implies that $\frac{\partial a_{0}^{*}}{\partial \beta}>0$.

Proof. Proposition 2: Define the function,

$$
\Upsilon=a-1+\frac{c}{(1-\lambda) \beta\left[\rho \theta L_{1}(a)+(1-\rho) L_{0}(a)\right]},
$$

where,

$$
L_{0}(a)=\frac{\lambda\left(V_{h}-V_{\ell}\right)}{\lambda(1+\beta)+(1-\lambda)(1-a)}, \text { and } L_{1}(a)=\frac{\lambda(1-\theta)\left(V_{h}-V_{\ell}\right)}{\lambda(1+\beta)(1-\theta)+(1-\lambda) \theta(1-a)} .
$$

The interior solution is given by $a^{*} \in(0,1)$ that satisfies the condition $\Upsilon(a)=0$. First, we apply 
the Intermediate Value Theorem to establish the existence of the solution $a^{*} \in(0,1)$, by noting that $\Upsilon$ is continuous in $a$ and $\Upsilon(0)<0<\Upsilon(1)$, under the condition $c<c_{1}$, where

$$
\left.c_{1} \equiv \lambda\left(V_{h}-V_{\ell}\right)(1-\lambda) \beta\left[\rho \theta \frac{(1-\theta)}{\lambda(1+\beta)(1-\theta)+(1-\lambda) \theta}\right)+(1-\rho) \frac{1}{\lambda(1+\beta)+(1-\lambda)}\right] .
$$

In particular,

$$
\begin{aligned}
\Upsilon(0) & =-1+\frac{c}{(1-\lambda) \beta\left[\rho \theta L_{1}(0)+(1-\rho) L_{0}(0)\right]} \\
& =-1+\frac{c}{(1-\lambda) \beta\left[\rho \theta \frac{\lambda(1-\theta)\left(V_{h}-V_{\ell}\right)}{\lambda(1+\beta)(1-\theta)+(1-\lambda) \theta}+(1-\rho) \frac{\lambda\left(V_{h}-V_{\ell}\right)}{\lambda(1+\beta)+(1-\lambda)}\right]}<0 \text { for } c<c_{1} . \\
\Upsilon(1) & =\frac{c}{(1-\lambda) \beta\left[\rho \theta L_{1}(1)+(1-\rho) L_{0}(1)\right]} \\
& =\frac{c(1+\beta)}{\left(V_{h}-V_{\ell}\right)(1-\lambda) \beta(\rho \theta+1-\rho)}>0
\end{aligned}
$$

Thus, we conclude that for any $\rho \in(0,1)$ there exists at least one solution $a^{*} \in(0,1)$ such that $\Upsilon=0$.

Now that we have established existence, we turn to uniqueness by establishing that $\frac{\partial \Upsilon}{\partial a} \geq 0$. In particular, it follows from $\frac{\partial L_{1}(a)}{\partial a}>0$ and $\frac{\partial L_{0}(a)}{\partial a}>0$ that, for any $a \in(0,1)$,

$$
\frac{\partial \Upsilon}{\partial a}=1+<- \text { this should be minus sign } \frac{c\left[\rho \theta \frac{\partial L_{1}(a)}{\partial a}+(1-\rho) \frac{\partial L_{0}(a)}{\partial a}\right]}{(1-\lambda) \beta\left[\rho \theta L_{1}(a)+(1-\rho) L_{0}(a)\right]^{2}}>0
$$

Because $\left.\rho \theta L_{1}(a)+(1-\rho) L_{0}(a)\right]>0$, the function, $\Upsilon$, can be rewritten as follows:

$$
\Upsilon=c-(1-a)(1-\lambda) \beta\left[\rho \theta L_{1}(a)+(1-\rho) L_{0}(a)\right]
$$

Then,

$$
\begin{aligned}
\frac{\partial \Upsilon}{\partial a} & =(1-\lambda) \beta\left[\rho \theta L_{1}(a)+(1-\rho) L_{0}(a)\right]-(1-a)(1-\lambda) \beta\left[\rho \theta \frac{\partial L_{1}(a)}{\partial a}+(1-\rho) \frac{\partial L_{0}(a)}{\partial a}\right] \\
& =\lambda\left(V_{h}-V_{\ell}\right)\left\{\rho \theta \frac{\lambda(1-\theta)^{2}(1+\beta)}{[\lambda(1+\beta)(1-\theta)+(1-\lambda) \theta(1-a)]^{2}}+(1-\rho) \frac{\lambda(1+\beta)}{[\lambda(1+\beta)+(1-\lambda)(1-a)]^{2}}\right\}>0
\end{aligned}
$$


The equilibrium audit quality can be explicitly expressed as follows:

$$
\begin{aligned}
\frac{c}{(1-a)(1-\lambda)} & =\beta\left[\rho \theta L_{1}+(1-\rho) L_{0}\right] \\
& =\rho \theta \frac{\beta \lambda(1-\theta)\left(V_{h}-V_{\ell}\right)}{\lambda(1+\beta)(1-\theta)+(1-\lambda) \theta(1-a)}+(1-\rho) \frac{\beta \lambda\left(V_{h}-V_{\ell}\right)}{\lambda(1+\beta)+(1-\lambda)(1-a)}
\end{aligned}
$$

This simplifies to,

$$
\frac{c}{\beta \lambda\left(V_{h}-V_{\ell}\right)(1-a)(1-\lambda)}=\frac{\rho \theta(1-\theta)}{\lambda(1+\beta)(1-\theta)+(1-\lambda) \theta(1-a)}+\frac{(1-\rho)}{\lambda(1+\beta)+(1-\lambda)(1-a)} .
$$

or,

$$
\begin{aligned}
\frac{c}{\beta \lambda\left(V_{h}-V_{\ell}\right)(1-a)(1-\lambda)}= & \frac{\rho \theta(1-\theta) \lambda(1+\beta)+(1-\lambda)(1-a)]}{[\lambda(1+\beta)(1-\theta)+(1-\lambda) \theta(1-a)][\lambda(1+\beta)+(1-\lambda)(1-a)]} \\
& +\frac{(1-\rho)[\lambda(1+\beta)(1-\theta)+(1-\lambda) \theta(1-a)]}{[\lambda(1+\beta)(1-\theta)+(1-\lambda) \theta(1-a)][\lambda(1+\beta)+(1-\lambda)(1-a)]} .
\end{aligned}
$$

The numerator on the right-hand-side is,

$\rho \theta(1-\theta) \lambda(1+\beta)+\rho \theta(1-\theta)(1-\lambda)(1-a)+\lambda(1+\beta)(1-\theta)+(1-\lambda) \theta(1-a)-\rho \lambda(1+\beta)(1-\theta)-\rho(1-\lambda) \theta(1-a)$

This simplifies to,

$$
\lambda(1+\beta)(1-\theta)[1-\rho(1-\theta)]+(1-a)(1-\lambda) \theta[1-\rho \theta]
$$

Therefore, we have the following

$$
\begin{gathered}
\frac{c}{\beta \lambda\left(V_{h}-V_{\ell}\right)(1-a)(1-\lambda)}=\frac{\lambda(1+\beta)(1-\theta)[1-\rho(1-\theta)]+(1-a)(1-\lambda) \theta[1-\rho \theta]}{[\lambda(1+\beta)(1-\theta)+(1-\lambda) \theta(1-a)][\lambda(1+\beta)+(1-\lambda)(1-a)]} \Rightarrow \\
\quad \frac{c[\lambda(1+\beta)(1-\theta)+(1-\lambda) \theta(1-a)][\lambda(1+\beta)+(1-\lambda)(1-a)]}{\beta \lambda\left(V_{h}-V_{\ell}\right)(1-\lambda)} \\
=(1-a) \lambda(1+\beta)(1-\theta)[1-\rho(1-\theta)]+(1-a)^{2}(1-\lambda) \theta[1-\rho \theta] .
\end{gathered}
$$


The numerator on the left-hand-side of the equation expands to,

$$
c\left[\begin{array}{c}
\lambda(1+\beta)(1-\theta) \lambda(1+\beta)+\lambda(1+\beta)(1-\theta)(1-\lambda)(1-a)+(1-\lambda) \theta(1-a) \lambda(1+\beta) \\
+(1-\lambda) \theta(1-a)(1-\lambda)(1-a)
\end{array}\right]
$$

This, in turn simplifies to,

$$
c\left[[\lambda(1+\beta)]^{2}(1-\theta)+(1-a) \lambda(1-\lambda)(1+\beta)+(1-a)^{2} \theta(1-\lambda)^{2}\right] .
$$

Thus, we reach the equation,

$$
\begin{aligned}
& \frac{c\left[[\lambda(1+\beta)]^{2}(1-\theta)+(1-a) \lambda(1-\lambda)(1+\beta)+(1-a)^{2} \theta(1-\lambda)^{2}\right]}{\beta \lambda\left(V_{h}-V_{\ell}\right)(1-\lambda)} \\
= & (1-a) \lambda(1+\beta)(1-\theta)[1-\rho(1-\theta)]+(1-a)^{2}(1-\lambda) \theta[1-\rho \theta] .
\end{aligned}
$$

This implies the following quadratic equation:

$$
\begin{aligned}
A & =\frac{c(1-\lambda) \theta}{\beta \lambda\left(V_{h}-V_{\ell}\right)}-(1-\lambda) \theta[1-\rho \theta] \\
B & =\frac{c(1+\beta)}{\beta\left(V_{h}-V_{\ell}\right)}-\lambda(1+\beta)(1-\theta)[1-\rho(1-\theta)] \\
C & =\frac{c \lambda(1+\beta)^{2}(1-\theta)}{\beta\left(V_{h}-V_{\ell}\right)(1-\lambda)}
\end{aligned}
$$

The solution is given by $1-a^{*}=\frac{-B-\sqrt{B^{2}-4 A C}}{2 A}>0$. This follows because $A<0$ for $c \leq c_{1}$.

\section{Proof. Corollary 2:}

Using the Implicit Function Theorem, the effect of the strictness of the legal liability regime on audit quality is:

$$
\frac{\partial a^{*}}{\partial \beta}=-\frac{\partial \Upsilon}{\partial \beta} / \frac{\partial \Upsilon}{\partial a}
$$

The above implies that,

$$
\begin{aligned}
\frac{\partial \Upsilon}{\partial \beta} & =-\frac{c}{(1-\lambda) \beta} \frac{\left[\rho \theta L_{1}(a)+(1-\rho) L_{0}(a)\right]+\beta\left[\rho \theta \frac{\partial L_{1}(a)}{\partial \beta}+(1-\rho) \frac{\partial L_{0}(a)}{\partial \beta}\right]}{\left[\rho \theta L_{1}(a)+(1-\rho) L_{0}(a)\right]^{2}} \\
& =-\frac{c\left(V_{h}-V_{\ell}\right)}{(1-\lambda) \beta\left[\rho \theta L_{1}(a)+(1-\rho) L_{0}(a)\right]^{2}}\left[\frac{\lambda_{1}}{\left(1+\beta \lambda_{1}\right)^{2}}+\frac{\lambda_{0}}{\left(1+\beta \lambda_{0}\right)^{2}}\right]<0
\end{aligned}
$$

From the proof of Proposition $2 \frac{\partial \Upsilon}{\partial a}>0$, which implies that $\frac{\partial a^{*}}{\partial \beta}>0$. 
Turning to the effect of informed trading on audit quality,

$$
\frac{\partial a^{*}}{\partial \rho}=-\frac{\partial \Upsilon}{\partial \rho} / \frac{\partial \Upsilon}{\partial a}
$$

The above implies that,

$$
\frac{\partial \Upsilon}{\partial \rho}=-\frac{c}{(1-\lambda) \beta} \frac{\theta L_{1}(a)-L_{0}(a)}{\left[\rho \theta L_{1}(a)+(1-\rho) L_{0}(a)\right]^{2}} \geq 0
$$

The above inequality follows from the following relation between $\theta L_{1}(a)$ and $L_{0}(a)$ :

$$
\begin{aligned}
\theta L_{1}(a) & =\frac{\beta \lambda_{1} \theta}{1+\beta \lambda_{1}}\left(V_{h}-V_{\ell}\right)=\frac{\beta \lambda \theta(1-\theta)\left(V_{h}-V_{\ell}\right)}{\lambda(1+\beta)(1-\theta)+(1-\lambda) \theta(1-a)} \\
& \leq \frac{\beta \lambda\left(V_{h}-V_{\ell}\right)}{\lambda(1+\beta)+(1-\lambda)(1-a)+\beta \lambda}=L_{0}(a) .
\end{aligned}
$$

From the proof of Proposition $2 \frac{\partial \Upsilon}{\partial a} \geq 0$, which implies that $\frac{\partial a^{*}}{\partial \rho} \leq 0$.

Finally, the relation between audit quality and the likelihood of the liquidity shock is

$$
\frac{\partial a}{\partial \theta}=-\frac{\partial \Upsilon}{\partial \theta} / \frac{\partial \Upsilon}{\partial a}
$$

The above implies that,

$$
\frac{\partial \Upsilon}{\partial \theta}=-\frac{c}{(1-\lambda) \beta} \frac{\rho \frac{\partial\left[\theta L_{1}(a)\right]}{\partial \theta}}{\left[\rho \theta L_{1}(a)+(1-\rho) L_{0}(a)\right]^{2}} .
$$

It is useful to note that the function $\theta L_{1}(a)$ equals zero for $\theta=0,1$ and is strictly positive for intermediate values of $\theta$. Further, since there are at most two solutions to the equation $\frac{\partial\left[\theta L_{1}(a)\right]}{\partial \theta}=0$, there can only be one such solution in the unit interval $\theta \in(0,1)$, as the function equals zero at both end points. This implies that there exists a unique $\bar{\theta} \in(0,1)$ for which $\frac{\partial\left[\theta L_{1}(a)\right]}{\partial \theta}>0$ for all $0<\theta<\bar{\theta}$ and $\frac{\partial\left[\theta L_{1}(a)\right]}{\partial \theta}<0$ for all $\bar{\theta}<\theta<1$. Equivalently, $\frac{\partial \Upsilon}{\partial \theta}<0$ for all $0<\theta<\bar{\theta}$ and $\frac{\partial \Upsilon}{\partial \theta}>0$ for all $\bar{\theta}<\theta<1$. Thus, because $\frac{\partial \Upsilon}{\partial a} \geq 0$ (from the proof of Proposition 2), we can conclude that,

$$
\frac{\partial a}{\partial \theta} \geq 0 \text { for } 0<\theta<\bar{\theta} \text { and } \frac{\partial a}{\partial \theta} \leq 0 \text { for } \bar{\theta}<\theta<1 \text {, provided that the solution is interior. }
$$

Proof. Lemma 1: To better understand the profit in (18), notice that when the strategic trader 
purchases undervalued shares the price differential is,

$$
P_{2}\left(s_{h}, F=0\right)-P_{3}\left(V_{\ell}, s_{h}, F=0\right)=\frac{\lambda_{1} V_{h}+\left(1-\lambda_{1}\right) V_{\ell}+\beta \lambda_{1} V_{h}}{1+\beta \lambda_{1}}-\frac{V_{\ell}+\beta \lambda_{1} V_{h}}{1+\beta \lambda_{1}}=\frac{\lambda_{1}\left(V_{h}-V_{\ell}\right)}{1+\beta \lambda_{1}}
$$

and when she sells over-valued shares it is,

$$
P_{3}\left(V_{h}, s_{h}\right)-P_{2}\left(s_{h}, F=0\right)=V_{h}-\frac{\lambda_{1} V_{h}+\left(1-\lambda_{1}\right) V_{\ell}+\beta \lambda_{1} V_{h}}{1+\beta \lambda_{1}}=\frac{\left(1-\lambda_{1}\right)\left(V_{h}-V_{\ell}\right)}{1+\beta \lambda_{1}}
$$

Provided that the chosen likelihood of being informed is $\rho$ and the equilibrium size of trade is $\Delta$, this implies an expected profit of,

$$
E \pi^{\inf }=\rho \Delta\left[\frac{\left[\lambda_{1}(1-\lambda)(1-\hat{a}) \theta+\left(1-\lambda_{1}\right) \lambda(1-\theta)\right]\left(V_{h}-V_{\ell}\right)}{1+\beta \lambda_{1}}\right]
$$

Substituting the value for $\lambda_{1}$ implies that,

$$
\begin{aligned}
E \pi^{\mathrm{inf}} & =\rho \Delta\left[\frac{\left[\lambda(1-\theta)[(1-\lambda)(1-\hat{a}) \theta+\lambda(1-\theta)+(1-\lambda) \theta(1-\hat{a})-\lambda(1-\theta)]\left(V_{h}-V_{\ell}\right)\right.}{\lambda(1-\theta)+(1-\lambda) \theta(1-\hat{a})+\beta \lambda(1-\theta)}\right] \\
& =\frac{2 \rho \Delta \lambda(1-\lambda) \theta(1-\theta)(1-\hat{a})\left(V_{h}-V_{\ell}\right)}{\lambda(1-\theta)(1+\beta)+(1-\lambda) \theta(1-\hat{a})} .
\end{aligned}
$$

This implies the following expected payoff, while substituting for $\lambda_{1}$ and considering the cost of information production by the strategic investor:

$$
U^{S}(\hat{a})=\rho \Delta\left(V_{h}-V_{\ell}\right) \frac{2 \lambda(1-\lambda) \theta(1-\theta)(1-\hat{a})}{\lambda(1+\beta)(1-\theta)+(1-\lambda) \theta(1-\hat{a})}+\kappa \ln (1-\rho)
$$

Then the first order condition is $\rho(\hat{a})=\max \left(1-\frac{\kappa}{\Delta\left(V_{h}-V_{\ell}\right)} \frac{[\lambda(1+\beta)(1-\theta)+(1-\lambda) \theta(1-\hat{a})]}{2 \lambda(1-\lambda) \theta(1-\theta)(1-\hat{a})}, 0\right)$.

The effect of the conjectured audit quality on the strategic trader's information production is:

$$
\begin{aligned}
\frac{\partial \rho}{\partial \hat{a}} & =-\frac{\kappa}{\Delta\left(V_{h}-V_{\ell}\right)}\left\{\frac{-2 \lambda(1-\lambda)^{2} \theta^{2}(1-\theta)(1-\hat{a})+2 \lambda(1-\lambda) \theta(1-\theta)[\lambda(1+\beta)(1-\theta)+(1-\lambda) \theta(1-\hat{a})]}{[2 \lambda(1-\lambda) \theta(1-\theta)(1-\hat{a})]^{2}}\right\} \\
& =-\frac{2 \lambda(1-\lambda) \theta(1-\theta) \kappa}{\Delta\left(V_{h}-V_{\ell}\right)} \frac{\lambda(1+\beta)(1-\theta)}{[2 \lambda(1-\lambda) \theta(1-\theta)(1-\hat{a})]^{2}}<0
\end{aligned}
$$

By inspection, an increase in the strictness of the legal liability regime, $\beta$, causes the strategic trader's information production, $\rho(\hat{a})$, to decrease.

Turning to the effect of the likelihood of the liquidity shock, 


$$
\frac{\partial \rho}{\partial \theta}=-\frac{2 \lambda(1-\lambda)(1-\hat{a}) \kappa}{\Delta\left(V_{h}-V_{\ell}\right)} \frac{\left[-\lambda(1+\beta)(1-\theta)^{2}+(1-\lambda) \theta^{2}(1-\hat{a})\right]}{[2 \lambda(1-\lambda) \theta(1-\theta)(1-\hat{a})]^{2}} .
$$

When $\theta=0,1$, then $\rho(\hat{a})=0$. However, as $\theta$ approaches $0, \frac{\partial \rho}{\partial \theta}$ is positive, and as $\theta$ approaches 1, $\frac{\partial \rho}{\partial \theta}$ is negative. Because there are at most two solutions to the equation $\frac{\partial \rho}{\partial \theta}=0$, there can only be one such solution in the unit interval $\theta \in(0,1)$, as the function equals zero at both end points, and is first increasing, and then decreasing. This implies that there exists a unique $\widehat{\theta} \in(0,1)$ for which $\frac{\partial \rho}{\partial \theta}>0$ for all $0<\theta<\widehat{\theta}$ and $\frac{\partial \rho}{\partial \theta}<0$ for all $\widehat{\theta}<\theta<1$,provided that the solution is interior.

Proof. Proposition 3: This equilibrium is summarized by the following requirements:

$$
\begin{aligned}
1-\rho^{*}(a) & =\min \left(1, \frac{\lambda(1+\beta)(1-\theta)+(1-\lambda) \theta(1-a)}{\frac{\Delta}{\kappa}\left(V_{h}-V_{\ell}\right) 2(1-\lambda) \theta(1-a) \lambda(1-\theta)}\right) \\
1-a^{*}(\rho) & =\min \left(1, \frac{c}{(1-\lambda)\left(\rho \theta L_{1}+(1-\rho) L_{0}\right)}\right) \text { where } \\
L_{1} & =\frac{\beta \lambda(1-\theta)\left(V_{h}-V_{\ell}\right)}{\lambda(1+\beta)(1-\theta)+(1-\lambda) \theta\left(1-a^{*}(\rho)\right)} \\
L_{0} & =\frac{\beta \lambda\left(V_{h}-V_{\ell}\right)}{\lambda(1+\beta)+(1-\lambda)\left(1-a^{*}(\rho)\right)}
\end{aligned}
$$

It follows that the equilibrium solution can either be interior, i.e., $\left(a^{*}, \rho^{*}\right) \in(0,1)^{2}$, or could contain the corner solutions $a^{*}=0$ and/or $\rho^{*}=0$ (note, solutions of the type $a^{*}=1$ and/or $\rho^{*}=1$ are not possible given the strictly positive domain of the parameters). To show that an equilibrium exists, one should notice that $a^{*}(\rho) \in[0,1]$ for all $\rho \in[0,1]$, and $a^{*}(\cdot)$ is continuous. Furthermore, $\rho^{*}(a) \in[0,1]$ for all $a \in[0,1]$, and $\rho^{*}(\cdot)$ is continuous. These properties imply that a fixed point exists.

We turn now to the derivation of the fully internal equilibrium. As implied by the above equilibrium conditions, this interior solution satisfies $1-a^{*}(\rho)=\frac{c}{(1-\lambda)\left(\rho \theta L_{1}+(1-\rho) L_{0}\right)}$. It is, therefore, useful to expand the expression $\rho \theta L_{1}+(1-\rho) L_{0}$ as a function of $a$ by using the above response 
function $\rho^{*}(a)$, as follows,

$$
\begin{aligned}
& \rho \theta L_{1}+(1-\rho) L_{0}=\frac{\rho \theta(1-\theta)}{\lambda(1+\beta)(1-\theta)+(1-\lambda) \theta(1-\widehat{a})}+\frac{1-\rho}{\lambda(1+\beta)+(1-\lambda)(1-\widehat{a})} \\
& =\frac{\left(\frac{\Delta}{\kappa}\left(V_{h}-V_{\ell}\right)[2(1-\lambda) \theta(1-\widehat{a}) \lambda(1-\theta)]\right.}{\frac{\Delta}{\kappa}\left(V_{h}-V_{\ell}\right)[2(1-\lambda) \theta(1-\widehat{a}) \lambda(1-\theta)][\lambda(1+\beta)(1-\theta)+(1-\lambda) \theta(1-\widehat{a})]} \\
& -\frac{[(1+\beta)(1-\theta) \lambda+(1-\lambda) \theta(1-\widehat{a})]) \theta(1-\theta)}{\frac{\Delta}{\kappa}\left(V_{h}-V_{\ell}\right)[2(1-\lambda) \theta(1-\widehat{a}) \lambda(1-\theta)][\lambda(1+\beta)(1-\theta)+(1-\lambda) \theta(1-\widehat{a})]} \\
& +\frac{(1+\beta)(1-\theta) \lambda+(1-\lambda) \theta(1-\widehat{a})}{\frac{\Delta}{\kappa}\left(V_{h}-V_{\ell}\right)[2(1-\lambda) \theta(1-\widehat{a}) \lambda(1-\theta)][\lambda(1+\beta)+(1-\lambda)(1-\widehat{a})]} \\
& =\frac{\theta(1-\theta)}{\frac{\Delta}{\kappa}\left(V_{h}-V_{\ell}\right)[2(1-\lambda) \theta(1-\widehat{a}) \lambda(1-\theta)]}\left(\left(\frac{\frac{\Delta}{\kappa}\left(V_{h}-V_{\ell}\right)[2(1-\lambda) \theta(1-\widehat{a}) \lambda(1-\theta)]}{[\lambda(1+\beta)(1-\theta)+(1-\lambda) \theta(1-\widehat{a})]}-1\right)\right. \\
& \left.+\frac{(1+\beta)(1-\theta) \lambda+(1-\lambda) \theta(1-\widehat{a})}{\lambda(1+\beta)+(1-\lambda)(1-\widehat{a})}\right)
\end{aligned}
$$

This in turn implies that,

$$
1-a^{*}=\frac{c \frac{\Delta}{\kappa}\left(V_{h}-V_{\ell}\right)\left[2(1-\lambda) \theta\left(1-a^{*}\right) \lambda(1-\theta)\right]}{(1-\lambda) \beta \lambda\left(V_{h}-V_{\ell}\right)\left(\left(\frac{\frac{\Delta}{\kappa}\left(V_{h}-V_{\ell}\right)\left[2(1-\lambda) \theta\left(1-a^{*}\right) \lambda(1-\theta)\right]}{\left[\lambda(1+\beta)(1-\theta)+(1-\lambda) \theta\left(1-a^{*}\right)\right]}-1\right) \theta(1-\theta)+\frac{(1+\beta)(1-\theta) \lambda+(1-\lambda) \theta\left(1-a^{*}\right)}{\lambda(1+\beta)+(1-\lambda)\left(1-a^{*}\right)}\right)}
$$

Since in an interior solution $1-a^{*}>0$, the above condition implies that,

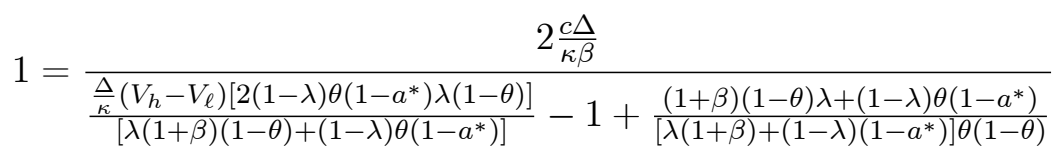

or,

$$
\frac{\frac{\Delta}{\kappa}\left(V_{h}-V_{\ell}\right)\left[2(1-\lambda) \theta\left(1-a^{*}\right) \lambda(1-\theta)\right]}{\left[\lambda(1+\beta)(1-\theta)+(1-\lambda) \theta\left(1-a^{*}\right)\right]}+\frac{(1+\beta)(1-\theta) \lambda+(1-\lambda) \theta\left(1-a^{*}\right)}{\theta(1-\theta)\left[\lambda(1+\beta)+(1-\lambda)\left(1-a^{*}\right)\right]}=\frac{c \Delta 2}{\kappa \beta}+1
$$

This simplifies to the following quadratic equation $A(1-a)^{2}+B(1-a)+C=0$, and we have the following coefficients for the solution $\left(1-a^{*}\right)$ :

$$
\begin{aligned}
A & =\theta^{2}(1-\lambda)^{2}\left[\frac{\Delta}{\kappa}\left(V_{h}-V_{\ell}\right) 2 \lambda(1-\theta)^{2}+\theta-\frac{c \Delta 2}{\kappa \beta}(1-\theta)\right] \\
B & =\theta(1-\theta)(1+\beta)(1-\lambda) \lambda\left[\frac{\Delta}{\kappa}\left(V_{h}-V_{\ell}\right) 2 \theta(1-\theta) \lambda+1-\frac{c \Delta 2}{\kappa \beta}\right] \\
C & =(\lambda(1+\beta)(1-\theta))^{2}\left[1-\left(\frac{c \Delta 2}{\kappa \beta}+1\right) \theta\right]
\end{aligned}
$$


Proof. Corollary 3: It follows from above that the level of audit quality is interior when $c<c_{2} \equiv$ $\frac{\theta(1-\theta)(1-\lambda) \lambda \beta\left(V_{h}-V_{\ell}\right)}{\lambda(1+\beta)(1-\theta)+\theta(1-\lambda)}$. Turning to the level of information production, the requirement $\rho\left(a_{0}^{*}\right)>0$ can be written as,

$$
\frac{\kappa}{\Delta\left(V_{h}-V_{\ell}\right)} \frac{(1+\beta)(1-\theta) \lambda+(1-\lambda) \theta\left(1-a_{0}^{*}\right)}{2(1-\lambda) \theta\left(1-a_{0}^{*}\right) \lambda(1-\theta)}<1
$$

After substituting the value $a_{0}^{*}=1-\frac{\lambda(1+\beta)}{(1-\lambda)\left[\frac{\lambda \beta}{c}\left(V_{h}-V_{\ell}\right)-1\right]}$, this implies that,

$$
(1+\beta)(1-\theta) \lambda<\frac{\lambda(1+\beta)}{(1-\lambda)\left[\frac{\lambda \beta}{c}\left(V_{h}-V_{\ell}\right)-1\right]}(1-\lambda) \theta\left[2 \lambda(1-\theta) \frac{\Delta\left(V_{h}-V_{\ell}\right)}{\kappa}-1\right]
$$

This can be further simplified as,

$$
\frac{1-\theta}{\theta}<\frac{\frac{2 \lambda(1-\theta) \Delta}{\kappa}\left(V_{h}-V_{\ell}\right)-1}{\frac{\lambda \beta}{c}\left(V_{h}-V_{\ell}\right)-1}
$$

This can be written as a condition on $\kappa<\kappa_{c}$ as follows,

$$
\kappa<\kappa_{c} \equiv \frac{2 \lambda(1-\theta) \Delta\left(V_{h}-V_{\ell}\right)}{\frac{1-\theta}{\theta}\left(\frac{\lambda \beta}{c}\left(V_{h}-V_{\ell}\right)-1\right)+1}
$$

Uniqueness follows from the fact that there are at most two interior solutions. Notice, that if both exist then this would imply that $\rho\left(a_{0}^{*}\right)=0$ (i.e., there does not exist a third internal solution) but this is not possible if $c \leq c_{1}$ and $\kappa<\kappa_{c}$.

Proof. Corollary 4: If $\beta$ increases, from Corollary 2, the auditor responds with higher audit quality, i.e. $a(\widehat{\rho})$ increases. Furthermore, by inspection, an increase in $\beta$ causes the strategic trader's information production to decrease, i.e., $\rho(\hat{a})$ decreases. In addition, from Lemma 1 , $\frac{\partial \rho}{\partial \hat{a}}<0$ Together, this implies that an increase in $\beta$ causes the equilibrium audit quality, $a^{*}$, to increase, and the equilibrium information production, $\rho^{*}$, to decrease.

Turning to the liquidity shock, from Corollary 2 , an increase in $\theta$ causes $a(\widehat{\rho})$ to first increase and then decrease, i.e., $a(\widehat{\rho})$ is hump-shaped in $\theta$. Similarly, from Lemma 1, $\rho(\hat{a})$ is hump-shaped in $\theta$. This together with the relation between $\rho(\hat{a})$ and $a(\widehat{\rho})$, i.e., $\frac{\partial \rho}{\partial \hat{a}}<0$ and $\frac{\partial a}{\partial \widehat{\rho}}<0$, then in equilibrium, both $a^{*}$ and $\rho^{*}$ are non-monotonic in $\theta$.

Proof. Proposition 4: If $\beta$ increases, the effect on the value of the growth option is:

$$
\frac{\partial a^{I n v *}}{\partial \beta}(1-\lambda) I>0
$$


From Corollary 1, $\frac{\partial a^{I n v *}}{\partial \beta}>0$, implying that the above inequality holds.

\section{Proof. Proposition 5:}

If $\pi<\operatorname{Min}\left\{\pi_{1}, \pi_{0}\right\}$ and if $\beta$ increases, then by inspection $V G_{1}^{L o w}$ decreases, because from Corollary $4, \frac{\partial \rho^{I n v *}}{\partial \beta}<0$.If $c>c_{1}^{I n v}$, then $a^{I n v *}=a^{*}=0$, and if $\beta$ increases, then $V G_{1}^{\text {Interm } 1}, V G_{1}^{\text {Interm } 2}$, and $V G_{1}^{H i g h}$ decrease because $\frac{\partial \rho^{I n v *}}{\partial \beta}<0$.

If $c \leq c_{1}^{I n v}$, then $a^{I n v *}>0$ and $a^{*}>0$. If $\theta>1 / 2$ and $\pi_{0} \leq \pi<\pi_{1}$ and if $\beta$ increases, the effect on the value of the firm's growth option is:

$$
\frac{\partial V G_{1}^{\text {Interm } 1}}{\partial \beta}=\frac{\partial \rho^{*}}{\partial \beta}\left[-\lambda(1-\theta)(\pi-I)+(1-\lambda)\left(1-a^{I n v *}\right) I\right]+\frac{\partial a^{\text {Inv* }}}{\partial \beta}\left(1-\rho^{*}\right)(1-\lambda) I
$$

From Corollary $4, \frac{\partial a^{I n v *}}{\partial \beta}>0$. Thus, $\frac{\partial V G_{1}^{I n t e r m ~} 1}{\partial \beta}>0$ if

$$
-\lambda(1-\theta)(\pi-I)+(1-\lambda)\left(1-a^{I n v *}\right) I<0
$$

Rearranging, this is

$$
\pi>\frac{\left[\lambda(1-\theta)(\pi-I)+(1-\lambda)\left(1-a^{I n v *}\right)\right] I}{\lambda}
$$

This inequality holds because, by assumption $\pi \geq \pi_{0}$, and $\frac{\left[\lambda(1-\theta)(\pi-I)+(1-\lambda)\left(1-a^{I n v *}\right)\right] I}{\lambda}<\pi_{0}$.

If $\theta<1 / 2$ and $\pi_{1} \leq \pi<\pi_{0}$ and if $\beta$ increases, the effect on the value of the firm's growth option is:

$\frac{\partial V G_{1}^{I n t e r m} 2}{\partial \beta}=\frac{\partial \rho^{I n v *}}{\partial \beta}\left[\lambda(\pi-I)-(1-\lambda) \theta\left(1-a^{*}\right) I\right]+\frac{\partial a^{*}}{\partial \beta} \rho^{*}(1-\lambda) \theta I$ Because $\lambda(\pi-I)-(1-\lambda) \theta(1-$ $\left.a^{*}\right) I>0$,then $\frac{\partial V G_{1}^{I n t e r m} 2}{\partial \beta}$ is either positive or negative.

If $\pi \geq \operatorname{Max}\left\{\pi_{1}, \pi_{0}\right\}$, and if $\beta$ increases, the effect on the value of the firm's growth option is:

$$
\frac{\partial V G_{1}^{H i g h}}{\partial \beta}=(1-\lambda) I\left\{\frac{\partial \rho^{I n v *}}{\partial \beta}\left(1-a^{I n v *}\right)(1-\theta)+\frac{\partial a^{I n v *}}{\partial \beta} I\left[\rho^{I n v *} \theta+\left(1-\rho^{I n v *}\right)\right]\right\}
$$

Similar to above, $\frac{\partial V G_{1}^{H i g h}}{\partial \beta}$ is either positive or negative. 


\section{References}

Ball, R. and P. Brown. 1968. An Empirical Evaluation of Accounting Income Numbers. Journal of Accounting Research 6(2): 159-178.

Beaver, W. 1968. The Information Content of Annual Earnings Announcements. Journal of Accounting Research 6(Supplement): 67-92.

Bernhardt, D., Hollifield, B., Hughson, E. 1995. Investment and Insider trading. Review of Financial Studies 8(2): 501-548.

Bond, P., I. Goldstein, and E. Prescott. 2010. Market-Based Corrective Actions. The Review of Financial Studies 23(2): 781-820.

Choi, J.-H., J.-B. Kim, X. Liu, and D. Simunic. 2008. Audit pricing, legal liability regimes, and big 4 premiums: theory and cross-country evidence. Contemporary Accounting Research 25(1): $55-99$.

Chordia, T. and A. Subrahmanyam. 2004. Order imbalance and individual stock returns: Theory and evidence. Journal of Financial Economics 72(3): 485-518.

Demski, J. and G. Feltham. 1994. Market response to financial reports. Journal of Accounting and Economics 17(1-2): 3-40.

Deng, M., N. Melumad, and T. Shibano. 2012. Auditors' Liability, Investments, and Capital Markets: A Potential Unintended Consequence of the Sarbanes-Oxley Act. Journal of Accounting Research 50(5): 1179-1215.

Dye, R. 1993. Auditing Standards, Legal Liability, and Auditor Wealth. Journal of Political Economy 101(5): 887-914.

Einhorn, E. 2018, Competing Information Sources, The Accounting Review, 93(4), 151-176.

Frenkel, S., I. Guttman, and I. Kremer. 2017. The effect of analyst coverage on corporate voluntary disclosures, price efficiency and liquidity. Working paper.

Glosten, L. and P. Milgrom. 1985. Bid, ask and transaction prices in a specialist market with heterogeneously informed traders. Journal of Financial Economics 14 (1): 71-100.

Goldstein, I. and L. Yang. 2017. Information disclosure in financial markets. Annual Review of Financial Economics. 9 101-125.

Griffin, J., J. Harris, and S. Topaloglu. 2003. The Dynamics of Institutional and Individual Trading. Journal of Finance 58(6): 2285-2320.

Grossman, S. and J. Stiglitz. 1980. On the Impossibility of Informationally Efficient Markets. The American Economic Review 70(3): 393-408. 
Kumar, P., N. Langberg, and K. Sivaramakrishnan. 2016. Voluntary disclosure with informed trading in the IPO market. Journal of Accounting Research 54(5) 1365-1394.

Kumar, P., N. Langberg, J. Oded, and K. Sivaramakrishnan. 2017. Voluntary disclosure and strategic stock repurchases. Journal of Accounting and Economics Vol 63(2) 207-230.

Kyle, A. 1985. Continuous Auctions and Insider Trading. Econometrica 53(6): 1315-1335.

Kyle, A. 1989. Informed Speculation with Imperfect Competition. Review of Economic Studies 56(3): $317-56$.

Laux, V. and D.P. Newman. 2010. The Accounting Review. 85(1): 261-285.

Lu, T., and H. Sapra. 2009. Auditor Conservatism and Investment Efficiency. The Accounting Review. 84(6) 1933-1958.

Lys, T. and R. Watts. 1994. Lawsuits against Auditors. Journal of Accounting Research 32(Supplement): 65-93.

Maug, E., 1998. Large shareholders as monitors: is there a tradeoff between liquidity and control? Journal of Finance 53(1): 65-98.

McNichols, M. and B. Trueman. 1994. Public disclosure, private information collection and short-term trading. Journal of Accounting and Economics 17(1-2): 69-94.

Newman, D.P., E. Patterson, and J.R. Smith 2005. The Role of Auditing in Investor Protection. The Accounting Review 80(1): 289-313.

Petrov E. 2016. Voluntary Disclosure and Informed Trading. Working paper.

Public Company Oversight Board (PCAOB). 2015. Concept Release On Audit Quality Indicators. https://pcaobus.org/Rulemaking/Docket\%20041/Release_2015_005.pdf (accessed July 3, 2018).

Rothenberg, N. 2018. Auditor reputation concerns, legal liability, and standards. Working Paper. University of Alberta.

Schwartz, R. 1997. Legal Regimes, Audit Quality and Investment. The Accounting Review 72(3): 385-406.

Verrecchia, R.E. 1982. Information Acquisition in a Noisy Rational Expectations Economy. Econometrica 50(6): 1415-30. 


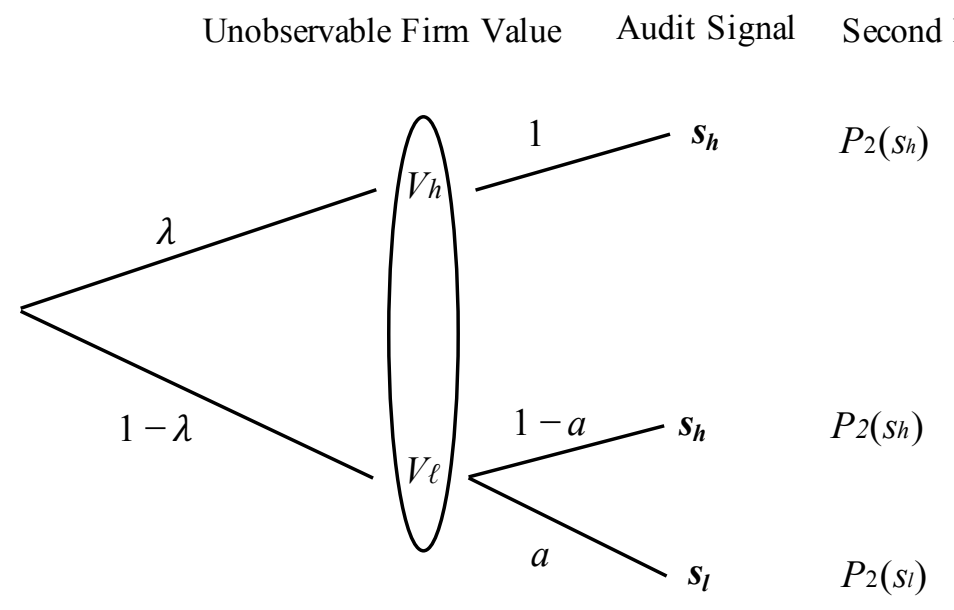

Panel A: Strategic trader is uninformed (with probability $1-\rho$ )

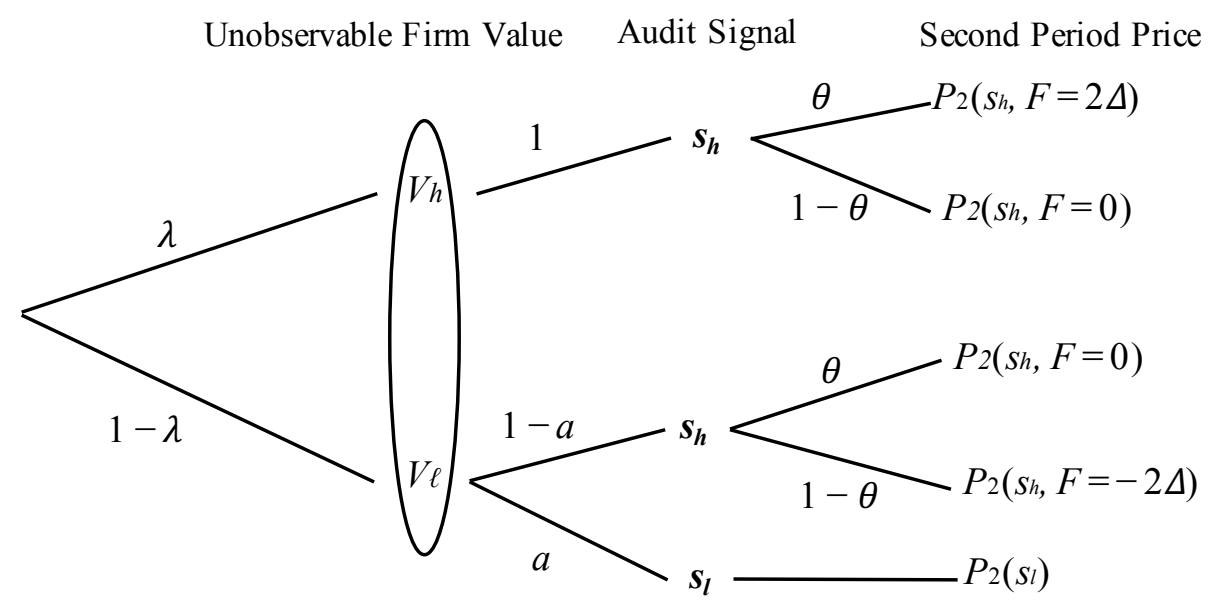

Panel B: Strategic trader informed (with probability $\rho$ )

Figure 1: The relation among the firm's value, the audit report, and the price at time $t=2$. 


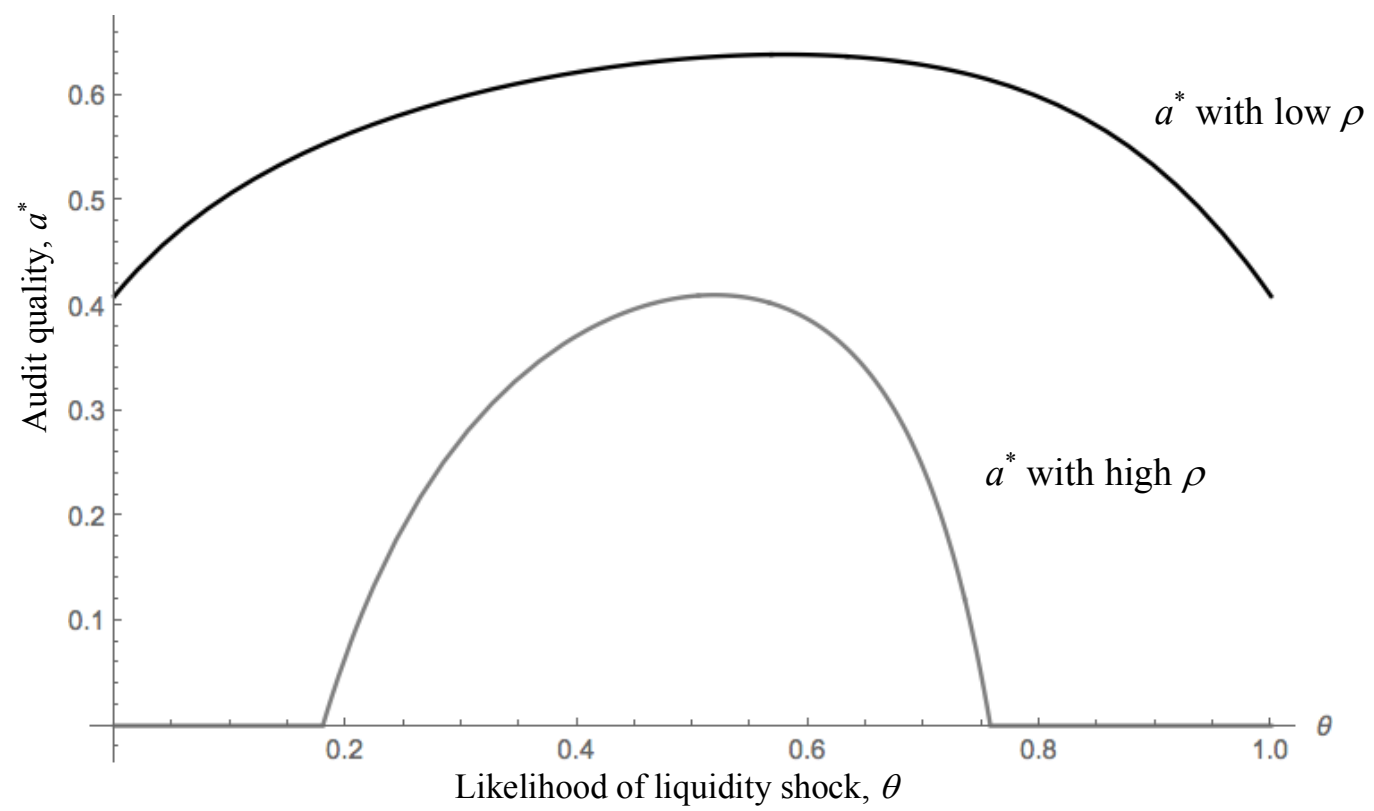

Figure 2: The effect of the likelihood of liquidity shock on audit quality with exogenous, informed trading. 

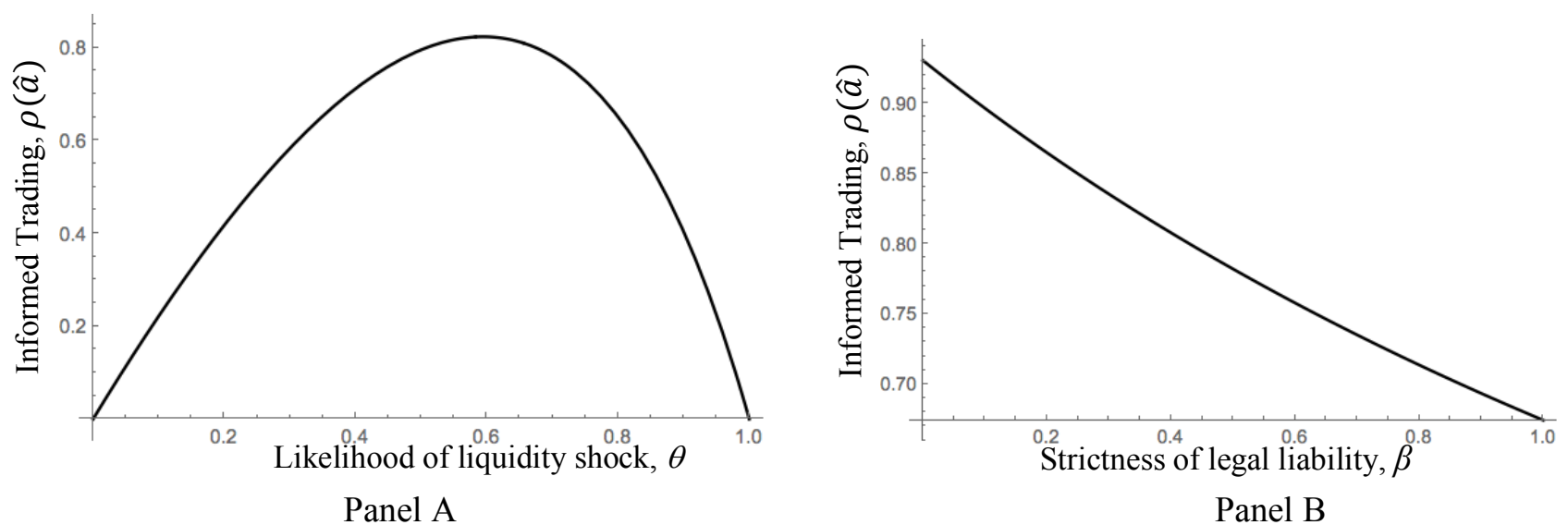

Figure 3: The effect of the likelihood of the liquidity shock, $\theta$, and the strictness of the legal liability regime, $\beta$, on the strategic trader's response function, $\rho(\hat{a})$ 


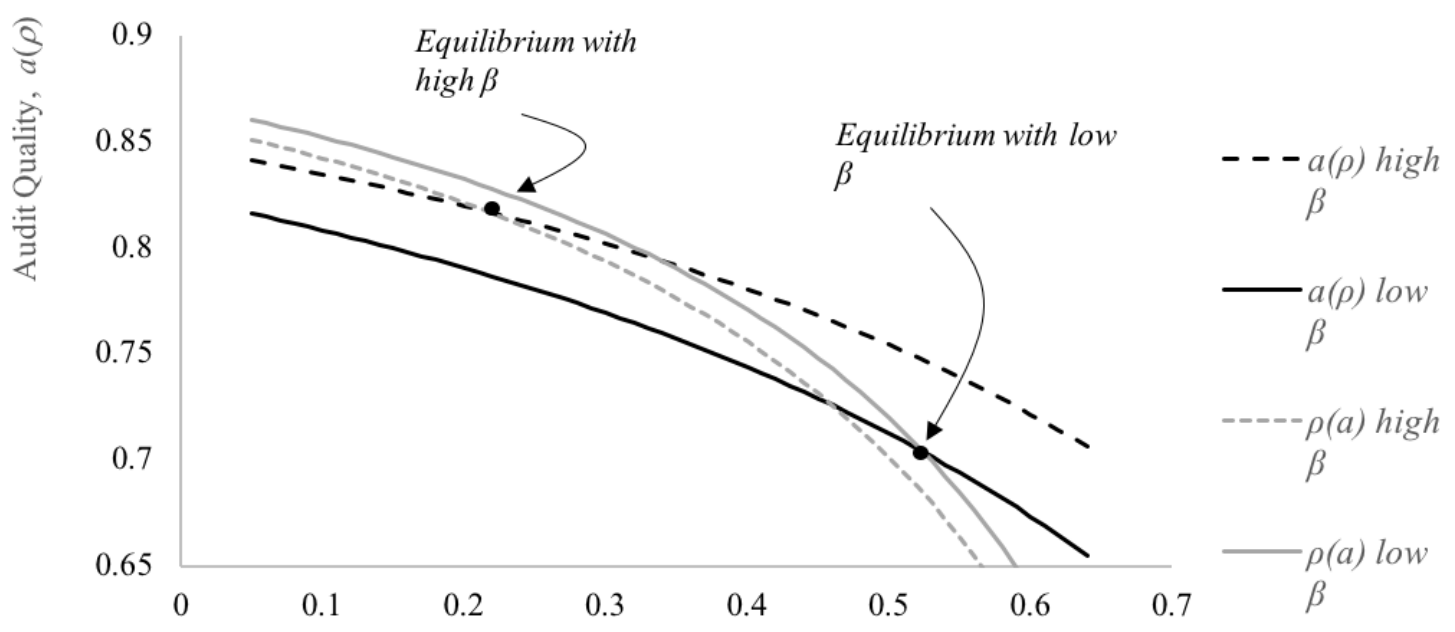

Likelihood of Informed Trading, $\rho(a)$

Figure 4: The auditor's response function, $a(\hat{\rho})$, and the strategic trader's response function, $\rho(\hat{a})$, with strict and lax legal liability, $\beta$. 


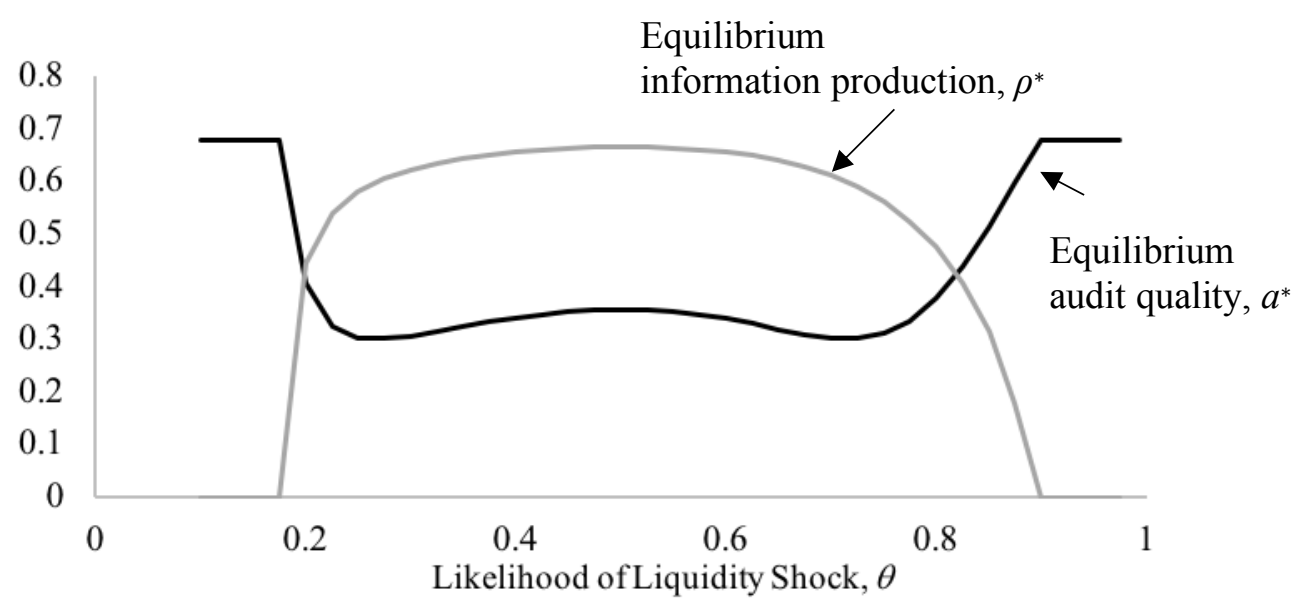

Figure 5: The effect of the likelihood of the liquidity shock, $\theta$ on the equilibrium levels, $a^{*}, \rho^{*}$. 


\section{Low Growth Firm}

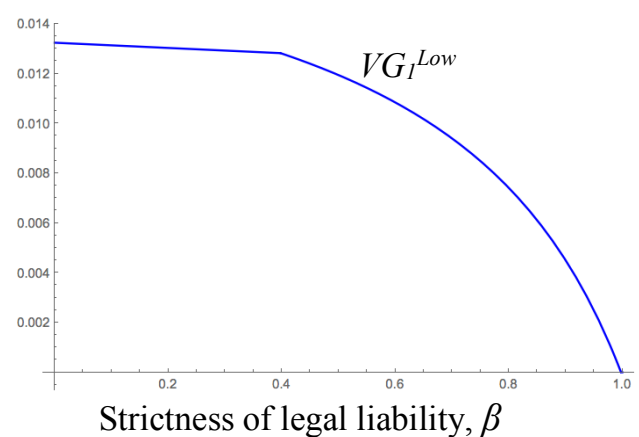

Panel A: Value of Growth Option

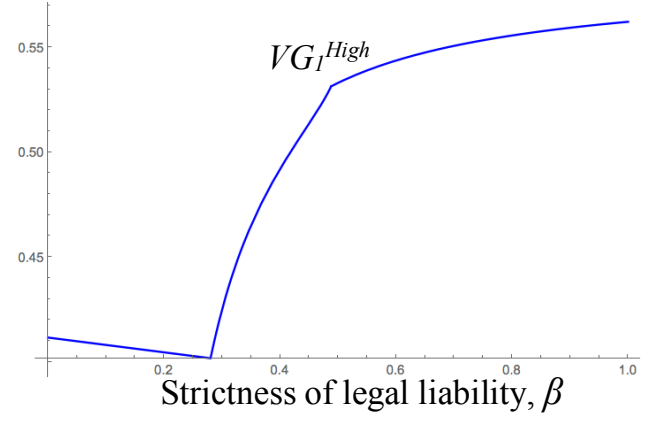

Panel C: Value of Growth Option

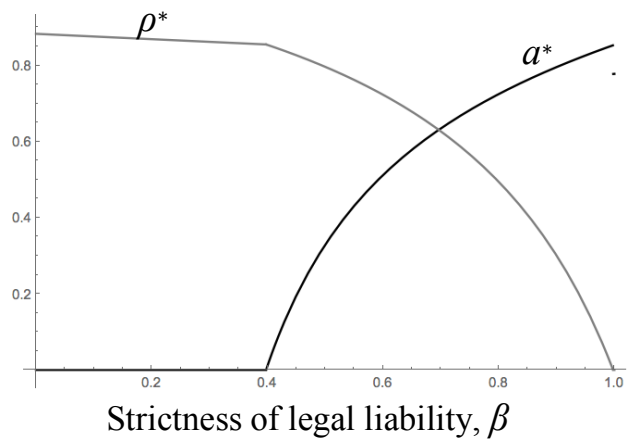

Panel B: Audit Quality and Information Production

\section{High Growth Firm}

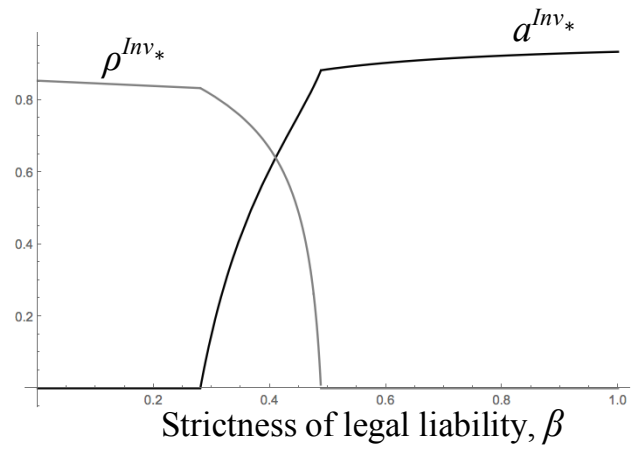

Panel D: Audit Quality and Information Production with

Figure 6: The effect of strictness of the legal liability regime, $\beta$, on the equilibrium levels, $a^{*}, \rho^{*}$, and the value of the growth option, $V G_{1}$. 